Western University

Scholarship@Western

Brain and Mind Institute Researchers'

Publications

Brain and Mind Institute

4-10-2019

\title{
The impact of individual differences on cross-language activation of meaning by phonology
}

\author{
Deanna C. Friessen \\ Faculty of Education, University of Western Ontario \\ Veronica Whitford \\ Department of Psychology, Brain and Mind Institute, Western University \\ Debra Titone \\ Department of Psychology, Centre for Research on Brain. Language and Music, McGill University \\ Debra Jared \\ Department of Psychology, Western University
}

Follow this and additional works at: https://ir.lib.uwo.ca/brainpub

Part of the Neurosciences Commons, and the Psychology Commons

\section{Citation of this paper:}

Friessen, Deanna C.; Whitford, Veronica; Titone, Debra; and Jared, Debra, "The impact of individual differences on cross-language activation of meaning by phonology" (2019). Brain and Mind Institute Researchers' Publications. 219.

https://ir.lib.uwo.ca/brainpub/219 


\section{Bilingualism: Language and Cognition}

\section{cambridge.org/bil}

\section{Research Article}

Cite this article: Friesen DC, Whitford V, Titone D, Jared D (2019). The impact of individual differences on cross-language activation of meaning by phonology. Bilingualism: Language and Cognition 1-21. https://doi.org/10.1017/S1366728919000142

Received: 14 September 2018

Revised: 20 February 2019

Accepted: 27 February 2019

\section{Key words:}

bilingualism; eye movements; reading; phonology; semantics; sentence processing

Address for correspondence:

Deanna C. Friesen, Email: Deanna.Friesen@ uwo.ca

\section{The impact of individual differences on cross-language activation of meaning by phonology}

\author{
Deanna C. Friesen ${ }^{1}$, Veronica Whitford ${ }^{2}$, Debra Titone ${ }^{3}$ and Debra Jared ${ }^{4}$
}

\footnotetext{
${ }^{1}$ Faculty of Education, University of Western Ontario; ${ }^{2}$ Department of Psychology, Brain and Mind Institute, University of Western Ontario; ${ }^{3}$ Department of Psychology, Centre for Research on Brain, Language and Music, McGill University and ${ }^{4}$ Department of Psychology, University of Western Ontario
}

We investigated how individual differences in language proficiency and executive control impact cross-language meaning activation through phonology. Ninety-six university students read English sentences that contained French target words. Target words were high- and lowfrequency French interlingual homophones (i.e., words that share pronunciation, but not meaning across langauges; mot means 'word' in French and sounds like 'mow' in English) and matched French control words (e.g., mois - 'month' in French). Readers could use the homophones' shared phonology to activate their English meanings and, ultimately, make sense of the sentence (e.g., Tony was too lazy to mot/mois the grass on Sunday). Shorter reading times were observed on interlingual homophones than control words, suggesting that phonological representations in one language activate cross-language semantic representations. Importantly, the magnitude of the effect was modulated by word frequency, and several participant-level characteristics, including French proficiency, English word knowledge, and executive control ability.

\section{Introduction}

There is compelling evidence that bilinguals activate information from both of their languages, even when reading in a single language (for recent reviews, see Jared, 2015; Lauro \& Schwartz, 2017; Sunderman \& Fancher, 2013; Titone, Whitford, Lijewska \& Itzhak, 2016; Whitford, Pivneva \& Titone, 2016). Much of this evidence comes from studies using words that share orthographic and/or phonological forms across languages, such as cognates (which also share meaning, e.g., table in English and French) and interlingual homographs (e.g., pain, which means 'bread' in French). Fewer studies have used words that share phonology across languages, such as interlingual homophones (e.g., mow in English and mot in French, which means 'word'). This research has found that a written word in one language activates phonological representations from both languages (e.g., Dijkstra, Grainger \& van Heuven, 1999; Haigh \& Jared, 2007; Jared \& Kroll, 2001). Phonological representations, in turn, can activate their associated semantic representations, even in the non-target language (e.g., Friesen \& Jared, 2012).

However, one limitation of the extant research on cross-language phonological activation in bilinguals is that it has exclusively focused on words presented in isolation through the use of response-based tasks (e.g., Friesen \& Jared, 2012). Importantly, such tasks may probe decisionmaking processes that are not involved in natural reading (Kuperman, Drieghe, Keuleers \& Brysbaert, 2013). Here, we used eye movement recordings, which provide a direct and temporally-sensitive measure of the cognitive processes implicated in word recognition to examine whether shared phonology between languages activates cross-language meaning. Furthermore, we also examined whether individual differences variables, such as language proficiency and executive control, modulate the magnitude of phonologically-mediated crosslanguage meaning activation, given that no published studies have examined the role of individual differences in cross-language activation of phonology.

We first briefly review the literature on phonological activation of word meanings using within-language (intralingual) homophones among monolinguals; this work motivated the methodological choices adopted in the current study. We then review the bilingual literature on phonological activation of word meanings using between-language (interlingual) homophones. Finally, we present an empirical study on whether shared phonology activates crosslanguage meaning and whether individual differences impact the nature of this activation.

\section{Within-language meaning activation by phonology}

Intralingual homophones are word pairs that share a pronunciation, but not meaning within a language (e.g., hear and here). If word meanings are activated just from orthographic 
representations, then only the meaning of a presented homophone should be activated. However, if word meanings are activated through phonology, then reading a homophone will result in the activation of both homophones' meanings. CATEgory VERIFICATION TASKS, wherein readers decide if target words are members of a category, reveal processing differences between homophones and their control words. On critical trials, the target word (e.g., rows, which sounds like rose) is not a member of the category (e.g., FLOWER); however, because its homophone mate is, readers are less accurate and slower to reject homophone foils as category members than spelling control words (e.g., robs; Friesen, Oh \& Bialystok, 2016; Jared \& Seidenberg, 1991; van Orden, 1987; van Orden, Johnston \& Hale, 1988; Ziegler, Benraïss \& Besson, 1999), indicating that the meanings of both homophones are activated and compete for selection. However, it is unclear from this response-based task whether phonological activation of meaning occurs during initial word recognition or during subsequent decision making processes.

The HOMOPHONE ERROR PARADIGM enables the investigation of both early- and late-stage processing. Here, homophones and their control words are placed into sentence contexts (e.g., The delegates flew here/hear/heat from Canada) to examine how phonology activates meaning during reading. Both eye-tracking (e.g., Daneman \& Reingold, 1993, Daneman, Reingold \& Davidson, 1995; Feng, Miller, Shu \& Zhang, 2001; Jared, Levy \& Rayner, 1999; Jared \& O’Donnell, 2017; Rayner, Pollatsek \& Binder, 1998) and event-related potential (ERP) data (e.g., Newman \& Connolly, 2004; Newman, Jared \& Haigh, 2012; Niznikiewicz \& Squires, 1996; Savill, Lindell, Booth, West \& Thierry, 2011) examine initial word processing by comparing early-stage fixation durations or ERP components, respectively.

Evidence that phonology contributes to the activation of word meanings comes from observations of shorter fixation durations or modulated ERP components (i.e., N200, N400) on homophones relative to spelling control words (e.g., hear vs. heat). However, the size of the homophone effect is typically larger when homophone pairs are visually similar, when both homophones are low-frequency words, and with less skilled readers (Jared et al., 1999; Jared \& Seidenberg, 1991). For the latter two, such effects are likely a consequence of weaker connection strengths or lower baseline activation levels arising from less word exposure (Dijkstra \& van Heuven, 2002; Gollan, Montoya, Cera \& Sandoval, 2008; Harm \& Seidenberg, 2004). That is, less exposure to words does not enable the connection strengths between a word's orthography and semantics to be firmly established and, consequently, the phonological pathway contributes more to word recognition than it does for high-frequency words. Furthermore, homophone errors are harder to detect when the context is highly constraining, indicating that representations associated with the correct homophone may be preactivated from top-down expectations (e.g., Jared \& Seidenberg, 1991; Rayner et al., 1998; Savill et al., 2011). Low constraint contexts thus provide clearer evidence about whether phonology computed from orthographic representations activates word meanings.

\section{Cross-language meaning activation by phonology}

Researchers have used interlingual homophones to investigate whether printed words in one language activate phonological representations in another language. Lexical decision, naming, and ERP studies have shown that processing of interlingual

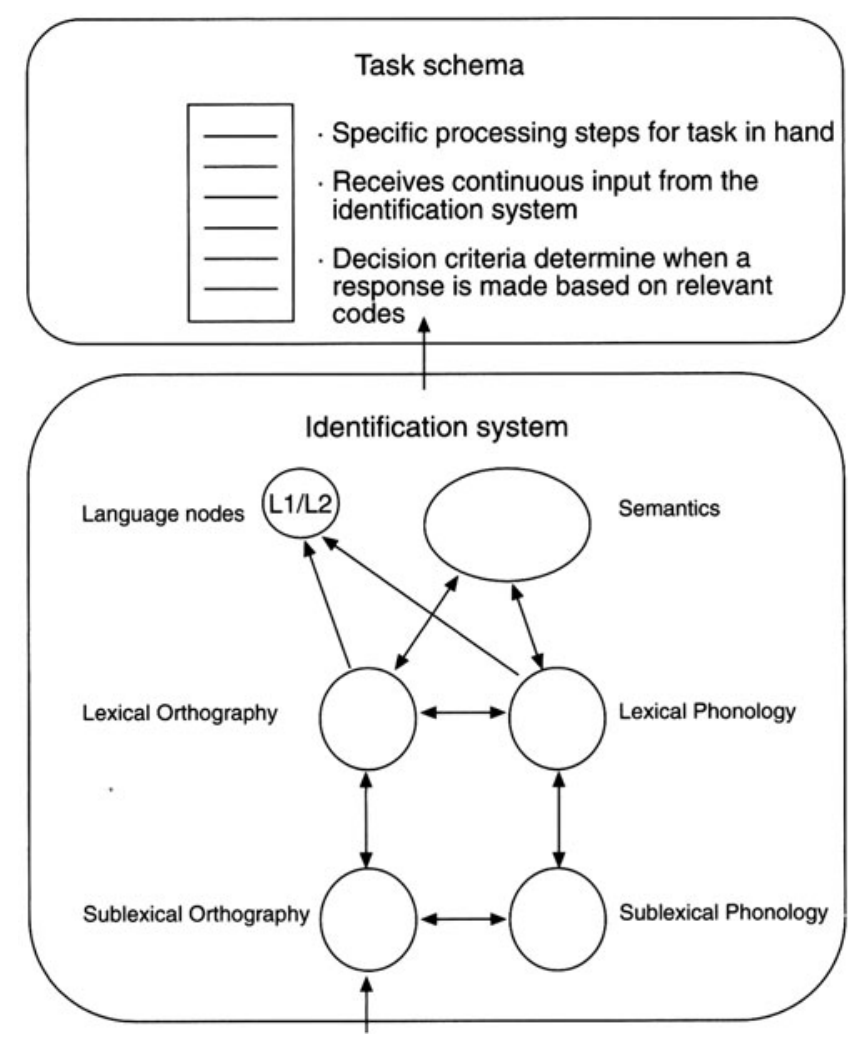

Figure 1. The Bilingual Interactive Activation+ Model $(B I A+)$ by Dijkstra and van Heuven (2002). Reproduced with permission of The Licensor through PLSclear.

homophones differs from that of spelling control words, particularly when participants perform the task in their second-language (L2) (e.g., Carrasco-Ortiz, Midgley \& Frenck-Mestre, 2012; Dijkstra et al., 1999; Friesen, Jared \& Haigh, 2014; Haigh \& Jared, 2007; Lemhöfer \& Dijkstra, 2004). Furthermore, masked primes in one language facilitate responses to phonologically similar target words in another language (e.g., Ando, Matsuki, Sheridan \& Jared, 2015; Ando, Jared, Nakayama \& Hino, 2014; Brysbaert, van Dyck \& van de Poel; 1999; Duyck, Diependaele, Drieghe \& Brysbaert, 2004; van Wijnendaele \& Brysbaert, 2002). These studies provide strong evidence for cross-language activation of phonology.

The Bilingual Interactive Activation Plus model (BIA+; Dijsktra \& van Heuven, 2002) can explain these phonological effects. Here, sublexical orthographic units activate their associated sublexical phonological units. The sublexical units then activate word-level representations in a language non-selective manner. Both lexical orthography and lexical phonology reciprocally activate each other and activate semantic knowledge; they also activate language nodes that identify the input's language membership. Because the model postulates no top-down suppression of the non-target language from these nodes, representations from both languages compete for selection and inhibit each other until one option is selected. For example, the French word mot activates its phonology which is shared with mow. Activation of this shared phonology then spreads to competing meanings (word and cut) before one is selected.

Although the BIA+ postulates that phonological representations activate their corresponding semantic representations in the non-target language, few studies have investigated whether non-target language phonological representations are SUFFICIENTLY activated such that they send a NOTICEABLE amount of activation 
to their corresponding semantic representation. In a priming study by Duyck (2005), Dutch-English bilinguals made faster lexical decisions on English words that were preceded by Dutch pseudohomophones of the English words' meaning (e.g, tauw is not a Dutch word, but is pronounced like the Dutch word touw 'rope' where 'rope' is the English target word). Friesen and Jared (2012) found that highly proficient bilinguals were slower and less accurate in deciding that interlingual homophones (shoe where chou means 'cabbage' in French) were not category members (e.g., vegetable) than spelling controls (e.g., silk) in both their first-language (L1) and L2. Degani, Prior, and Hajajra (2017) further demonstrated that cross-language semantic activation occurs when languages do not share a script. In a semantic relatedness judgment task, Arabic-Hebrew bilinguals saw Hebrew primes with the same pronunciation as an Arabic word (e.g., /sus/, 'horse' in Hebrew but 'chick' in Arabic), which were followed by Hebrew targets related to the Arabic meaning of the prime (e.g., the Hebrew word egg). Bilinguals were less accurate in judging these interlingual homophone primes and targets as unrelated in Hebrew compared to control pairs.

In these studies, phonological representations were sufficiently activated to activate their cross-language semantic representations. However, there are several limitations associated with these response-based tasks. First, in category verification, category names may provide top-down activation of meanings associated with exemplars and, thus, may overestimate the activation due to phonological representations in the non-target language. Second, it is unclear how to disentangle initial word recognition processes from selection processes in response-based tasks.

To date, only one study has examined how bilinguals process interlingual homophones embedded in sentence contexts to explore language non-selective semantic access. FitzPatrick and Indefrey (2014) had Dutch-English bilinguals listen to sentences that were either biased toward the target language (e.g., My cat is my favorite pet (pet sounds like hat in Dutch), biased toward the non-target language (e.g., The policeman wore a pet), or fully incongruent (e.g., Jeremy drove a pet) while ERPs were recorded. In both $\mathrm{L} 1$ and L2, the fully incongruent condition generated N400s (i.e., large negative deflections in neural waveforms elicited by semantic anomalies $\sim 400 \mathrm{~ms}$ post-stimulus onset), whereas the target language bias did not generate a N400. The non-target language biased condition generated an attenuated N400 in both languages, suggesting that both meanings of the homophones were active to some extent during sentence processing. However, as an auditory task, the word's phonology is presented and not generated from the orthography. Moreover, the sentences were highly constrained which may have generated top-down expectations.

\section{The present study}

In the current study, we used a bilingual HOMOPHONE ERROR PARADIGM with eye-tracking to probe both early- and late-stage phonological activation of cross-language meaning during visual word recognition. Sentences were written in English and on critical trials, the English homophone was presented or was replaced by either the French homophone or a French spelling control (e.g., Tony was too lazy to mow/mot ('word') /mois ('month') the grass on Sunday). When the French homophone (e.g., mot) was presented, the reader could make better sense of the sentence if they activated the English meaning of the shared phonology (e.g., 'cut'). This technique is akin to using English pseudohomophones and legal non-words to explore how spelling-sound correspondences activate meaning (e.g., Jared et al., 1999). The difference is that French homophones have meanings, and French experience may modulate these effects (as described below). Investigating how readers respond to errors is a useful tool in psycholinguistics to examine processing dynamics in visual word recognition.

To maximize the likelihood that the homophone effect was due to shared phonology and not top-down prediction from prior context, low constraint contexts were used. Although the sentence did not bias the reader towards the English word, overall it was the most plausible of the three meanings (e.g., Tony was too lazy to : 'cut', 'word','month'). Shorter fixations were expected on French homophones than on French control words even in these low constraint sentences because the English homophone meaning always fit. Additionally, both high- and low-frequency French homophones were employed. All English members of the interlingual homophone pairs were low-frequency words. If they had been high-frequency English words, they would have had familiar spellings making it difficult to observe any influence of phonology. In monolingual studies, homophone effects are more often observed on low-frequency words; individuals have less experience pairing orthography to meaning and, thus, likely engage the phonological pathway (Harm \& Seidenberg, 2004; Jared \& Seidenberg, 1991). However, in a bilingual scenario the impact of word frequency should interact with language experience in both languages.

To investigate how individual differences impact the dynamics of phonologically-mediated meaning activation, we measured language knowledge and executive control ability. A concern in bilingualism research is how monolingual and bilingual individuals are assigned to groups, as a function of their language background. Thus, we adopted a continuous, individual differences approach (Titone, Pivena, Sheikh, Webb \& Whitford, 2015; Whitford \& Luk, in press). Of note, our sample included individuals who did not consider themselves bilingual, although they did receive French instruction (as required by the Canadian education system). Thus, they were functionally monolingual, but could have used their knowledge of French spelling-sound correspondences to decode words in French. Since language non-selectivity effects are typically more clearly observed in highly proficient bilinguals, we expected that our core homophone effects might be weak when all participants were included in the analyses. However, we further expected that the individual differences in French proficiency would modulate the magnitude of homophone effects.

Eye-tracking studies using cognates and interlingual homographs embedded in sentences have provided evidence that lexical activation in bilinguals is initially language non-selective (e.g., Lemhöfer, Huestegge \& Mulder, 2018; Libben \& Titone, 2009; Pivneva, Mercier \& Titone, 2014; Schwartz \& Kroll, 2006; Titone, Libben, Mercier, Whitford \& Pivneva, 2011; van Assche, Drieghe, Duyck, Welvaert \& Hartsuiker, 2011; but see Hoversten \& Traxler, 2016). Particularly relevant here, several studies found that individual differences can modulate crosslanguage activation during sentence processing (Lemhöfer et al., 2018; Pivneva et al., 2014; Titone et al., 2011). For example, Titone and colleagues (2011) found that readers with an earlier L2 age of acquisition (AoA) exhibited greater language nonselectivity when reading sentences in their L1. Likewise, Pivneva and colleagues (2014) reported a reduced L1 impact on L2 sentence reading with greater L2 proficiency. The authors also found that greater domain-general executive control ability related 
to reduced interlingual homograph interference when reading low constraint L2 sentences. Extending this work, the current study examined whether individual differences in language proficiency and executive control modulate the extent to which crosslanguage meaning is activated through shared phonology.

Homophone effects should vary as a function of language proficiency. For a homophone effect to occur, readers must activate French spelling-sound correspondences (e.g., /mot/) and the corresponding English meaning of the shared phonology (e.g., mow 'to cut'). Accordingly, greater French decoding skills and English word knowledge should produce larger homophone effects. Homophone effects should also vary due to word frequency. For less proficient French users, homophone effects should be larger for high-frequency than for low-frequency words. High-frequency words benefit from more absolute exposure (although still low exposure) and, thus, the shared phonological representations may activate the English meanings. In contast, low-frequency words have received less absolute exposure and, thus, may activate shared phonological representations too weakly. For skilled users of French, homophone effects should be present for both high- and low-frequency words because they will have encountered both sufficiently often to develop strong connections between orthographic and phonological representations. Thus, we expected a larger impact of individual differences in language proficiency on low- versus high-frequency words.

Our predictions for executive control vary for early- versus late-stage reading. Pivneva and colleagues (2014) found that bilinguals with better executive control experienced less interlingual homograph interference, which, like our interlingual homophones, have different meanings across languages. Here, if participants inhibit their knowledge of French spelling-sound correspondences when reading the English sentences, then the difference between French interlingual homophones and control words should be reduced because neither French word will activate a corresponding English word. Similarly, if participants inhibit English lexical representations when encountering a French word, the English meaning of the homophone should be suppressed. In both cases, better executive control ability should result in smaller interlingual homophone effects. However, executive control might influence late-stage processing, as participants integrate the relevant meaning into the sentence. Here, better executive control may be associated with larger homophone effects. When anomalous words are encountered, readers may differ in the attention they deploy to resolve the error. For spelling control words, the information needed to resolve the anomaly may be less readily available than for homophones. Individuals with better executive control (i.e., ability to attend to relevant information) may engage in greater effort to resolve their understanding than individuals with weaker executive control ability.

\section{Method}

\section{Participants}

Ninety-six adults (25 males, 71 females; Age: $21.07 \pm 4.39$ years) participated for course credit or monetary compensation. Fifty-six participants were recruited from the University of Western Ontario (London, Ontario, Canada) and 40 from McGill University (Montréal, Québec, Canada). Participants were English speakers with varying degrees of French proficiency, ranging from minimal (e.g., required French courses) to native (e.g., acquired French as an L1). The study was approved by both institutions' research ethics boards.

\section{Materials and procedures}

Sentence-reading task

Thirty-six English-French interlingual homophone pairs were selected (e.g., mow and mot). Since there is no dictionary of Canadian French pronunciations (different from European French pronunciations), homophone selection was based on the authors' judgment of reasonable phonological similarity. Since vowels differ subtly between English and French, these homophone pairs are "close" rather than identical homophones. They have been used in prior work (Friesen \& Jared, 2012; Friesen et al., 2014; Haigh \& Jared, 2007). Using the Celex Corpus (Baayen, Piepenbrock \& van Rijn, 1993), the English homophones were low word form frequency (0-40 occurrences per million); using the Lexique database (New, Pallier, Brysbaert \& Ferrand, 2004), the French homophones were either low (2-52 occurrences per million) or high (76 -1061 occurrences per million) word form frequency. French control words were selected for the French homophones. To confirm that the French homophones were more phonologically similar to the English homophones than the French control words were, 13 proficient EnglishFrench bilinguals rated the phonological similarity of the English homophone to both the French homophone and the control word using a seven-point scale $(1=$ not at all to $7=$ identical $)$. An item analysis revealed that English homophones were rated as significantly more similar to French homophones than to the French control words, $(t(35)=24.61, p<.001)$. Otherwise, French homophones and their controls were matched for written word form frequency (parts per million), word length, English orthographic neighborhood size (Coltheart's N), English bigram frequency (N-Watch; Davis, 2005), orthographic similarity to their English homophone using van Orden's (1987) orthographic similarity metric, and semantic similarity to their English homophone (e.g., mow-mot (word) /mow-mois(month)) (all ps > .20). For the latter, Latent Semantic Analysis values (Landauer, Foltz \& Laham, 1998) were obtained from www.lsa.colorado.edu. See Table 1 for word characteristics. Since English homophones and French homophones are yoked, word characteristics cannot be matched. Data from the English homophones are provided as a reference, but were not included in the analyses.

For each of the 36 word triplets (i.e., English homophone, French homophone, and French control word), three English sentence frames were created (108 critical sentences total). Sentences were written such that the English homophone was a more plausible continuation of the sentence than either French word, but the sentence stem was not highly constrained (i.e., predictable). Plausibility judgments were collected from 26 native English speakers with little knowledge of French. Sentence stems were followed by a critical word, and raters indicated how plausible the critical word was as a continuation of the sentence using a fivepoint scale $(0=$ not at all, $1=$ a little, $2=$ moderately, $3=$ plausible, $4=$ very plausible). The French critical words were translated into English (e.g., Tony was too lazy to mow/word/month). Table 1 demonstrates that the English homophones were rated as significantly more plausible than the translations of the French words $(p s<.001)$. Moreover, there were no significant differences between the translations of French homophones and their control words on the plausibility ratings $(p>.34)$. To confirm that the target words were also not predictable from the sentence stems and, thus, were unlikely to be generated from top-down information, six additional native English speakers were given the sentence stems minus the critical words and asked to insert a 
Table 1. Word Characteristics (Means and Standard Deviations)

\begin{tabular}{|c|c|c|c|c|c|c|c|c|}
\hline Word Type & $\begin{array}{c}\text { Word } \\
\text { Frequency }\end{array}$ & $\begin{array}{l}\text { Word } \\
\text { Length }\end{array}$ & $\begin{array}{l}\text { Orthographic } \\
\text { Neighborhood }\end{array}$ & $\begin{array}{l}\text { English } \\
\text { Bigram } \\
\text { Tokens }\end{array}$ & $\begin{array}{c}\text { Phonological } \\
\text { Similarity }\end{array}$ & $\begin{array}{c}\text { Orthographic } \\
\text { Similarity }\end{array}$ & $\begin{array}{l}\text { Semantic } \\
\text { Similarity }\end{array}$ & Plausibility \\
\hline \multicolumn{9}{|l|}{ High Frequency } \\
\hline English Homophone & $15.6(13.6)$ & $3.7(0.8)$ & $11.6(5.8)$ & $2000(1541)$ & - & - & - & $3.0(0.5)$ \\
\hline French Homophone & $271.6(231.7)$ & $4.2(1.0)$ & $11.8(5.7)$ & $1491(1290)$ & $5.7(1.5)$ & $0.46(0.17)$ & $0.14(0.09)$ & $1.7(0.9)$ \\
\hline French Control & $270.5(264.4)$ & $4.2(0.9)$ & $9.3(5.1)$ & $1367(1072)$ & $1.4(0.7)$ & $0.45(0.15)$ & $0.11(0.08)$ & $1.5(0.9)$ \\
\hline \multicolumn{9}{|l|}{ Low Frequency } \\
\hline English Homophone & $12.4(12.8)$ & $3.9(0.7)$ & $8.2(6.1)$ & $1271(797)$ & - & - & - & $3.0(0.4)$ \\
\hline French Homophone & $21.0(14.4)$ & $4.5(0.8)$ & $8.3(4.8)$ & $1029(1049)$ & $5.7(1.5)$ & $0.41(0.20)$ & $0.10(0.07)$ & $1.7(0.8)$ \\
\hline French Control & $21.3(10.1)$ & $4.7(1.0)$ & $6.9(4.6)$ & $1024(795)$ & $1.7(1.3)$ & $0.41(0.21)$ & $0.10(0.08)$ & $1.5(0.9)$ \\
\hline
\end{tabular}

Table 2. Example of a Stimuli Triplet

\begin{tabular}{l}
\hline List $\mathbf{1}$ \\
\hline A Nathan had to pick up the toys before he could mow the lawn safely. \\
\hline B Phillip was unable to mot the field of hay because it was raining. \\
\hline C Tony was too lazy to mois the grass on Sunday. \\
\hline List $\mathbf{2}$ \\
\hline A Nathan had to pick up the toys before he could mot the lawn safely. \\
\hline B Phillip was unable to mois the field of hay because it was raining. \\
\hline C Tony was too lazy to mow the grass on Sunday. \\
\hline List $\mathbf{3}$ \\
\hline A Nathan had to pick up the toys before he could mois the lawn safely. \\
\hline B Phillip was unable to mow the field of hay because it was raining. \\
\hline C Tony was too lazy to mot the grass on Sunday.
\end{tabular}

single word (e.g., Tony was too lazy to ___ Of the 108 sentences, the target word was chosen by a single participant in five cases. For two sentences, three participants inserted the target word; otherwise, no English homophones were inserted (i.e., overall the correct English word was selected $1.7 \%$ of the time).

Participants saw each target word in one of the three sentence frames that were written for each triplet, and no sentence frame was seen twice. Three lists were created such that each word was presented in each sentence frame across the entire experiment (see Table 2 for an example). Each participant saw only one list. An additional 132 English filler sentences were created to decrease the percentage of sentences with a French word to $30 \%$ across the experiment (15\% homophones, $15 \%$ French control words). Of all the words presented in the sentences, participants encountered a French word only $2.6 \%$ of the time. The 240 trials were divided into three blocks of 80 trials ( 36 critical trials, 44 filler trials), which were counterbalanced. Each member of a stimulus triplet was presented in a different block to minimize repetition effects. A yes-no comprehension question appeared after each critical sentence and after $50 \%$ of filler sentences to ensure that participants were reading for meaning (e.g., Is the grass on Tony's lawn long?). Participants were instructed to read the sentences silently and naturally for comprehension.

An EyeLink 1000 desktop-mounted system was used to collect the eye movement data (right eye only) at a $1 \mathrm{kHz}$ sampling rate
(SR-Research, Ontario, Canada). Sentences were presented on a 21-inch CRT monitor, positioned $60 \mathrm{~cm}$ from participants' eyes. Calibration was performed at the beginning of each block (and as needed) using a five-point cross formation. Sentences were presented as single lines of text in black 10-point Courier New font against a light gray background.

\section{Language experience questionnaire (LEQ)}

Self-report measures of English and French language experience were obtained through a LEQ. Participants reported their age of language acquisition (i.e., AoA), which language they knew best, the proportion of time they used each language, and in what contexts. Participants rated their current level of fluency in listening, speaking, reading, and writing in both languages on a ten-point scale $(1=$ none to $10=$ native-like $)$.

\section{Test of word reading efficiency (TOWRE)}

The TOWRE is a timed measure of English reading fluency (Torgesen, Wagner \& Rashotte, 1999). Participants read aloud as many items on a card as possible in 45 seconds. Credit for a correct word was given if the word was read fluently and each phoneme was present. High scores reflect greater word reading fluency. Four versions were administered: English word reading (max score: 104); French word reading ( $\max$ score: 104); English non-word reading (max score: 63); and French non-word reading (max score: 63 ). French versions were not standardized, and were originally developed and used in prior work (Jared, Cormier, Levy \& Wade-Woolley, 2011). The TOWRE measures were selected because individual differences in the ability to rapidly extract phonology from print should underlie differences in the activation of shared phonological representations.

\section{Semantic judgment task}

The semantic judgment task assessed word knowledge in both English and French. One hundred nouns, 50 of which represented living things and 50 of which represented non-living things (i.e., objects) were selected in both English and French. Different items were selected in each language. The two categories were matched on written word form frequency and word length within each language and across languages ( $p s>.25)$. Words were presented one at a time on a computer screen; participants decided whether they were living or an object as quickly and accurately as possible with a button press. Response keys were counterbalanced. For accuracy, $d$-prime scores were calculated. Higher scores reflect greater word 
Table 3. Participant Characteristics and Behavioral Measures

\begin{tabular}{|c|c|c|c|c|}
\hline & \multicolumn{2}{|c|}{ English } & \multicolumn{2}{|c|}{ French } \\
\hline & Mean (SD) & Range & Mean (SD) & Range \\
\hline \multicolumn{5}{|l|}{ Self-Report } \\
\hline AoA (years) & $3.4(3.6)$ & $0-19$ & $5.4(4.2)$ & $0-23$ \\
\hline Current Use (\%) & $79.4(23.6)$ & $10-100$ & $20.5(24.3)$ & $0-90$ \\
\hline TOWRE Words (max. 104) & $87.7(11.6)$ & $57-104$ & $72.8(20.8)$ & $26-104$ \\
\hline TOWRE Non-Words (max. 63) & $54.3(5.8)$ & $39-63$ & $51.9(9.1)$ & $30-63$ \\
\hline \multicolumn{5}{|l|}{ Word Semantic Knowledge } \\
\hline Accuracy (d prime) & $3.51(1.42)$ & $1.05-6.05$ & $1.61(1.35)$ & $-0.49-5.48$ \\
\hline Reaction Time (ms) & $435(83)$ & & & $47(42)$ \\
\hline Error Rate (\%) & $3.2(7.9)$ & & & $7.1(7.8)$ \\
\hline
\end{tabular}

Note: $A \circ A=$ age of acquisition

knowledge. The semantic judgment task was selected because it measures knowledge of word meaning and individual differences in semantic knowledge should impact whether the cross-language meaning is activated by shared phonology. If readers do not have knowledge of the meaning associated with the shared phonology in English, then cross-language meaning activation is unlikely.

\section{Simon arrows task}

Participants performed a non-linguistic Simon arrow task. Arrows appeared on the left, right, or center of the screen; participants indicated the direction of the arrows and ignored their location. Congruency was manipulated by having the stimulus location and its response location match or mismatch. There were 40 trials of each type, and participants responded as quickly and accurately as possible with a button press. To calculate the magnitude of the Simon effects, participants' mean reaction time (RT) and number of errors in the congruent condition were subtracted from corresponding value in the incongruent condition and then divided by the congruent condition value. Larger values reflect larger Simon Effects and, thus, poorer executive control. The Simon Arrows task was selected because it assesses cognitive inhibition - the ability to ignore irrelevant information (location) and attend to relevant information (direction) (Martin-Rhee \& Bialystok, 2008). Since readers must both select the relevant meaning of the shared phonology and attend to relevant information to understand the sentences, differences in this executive control ability may modulate how readers process critical stimuli.

\section{Procedure}

The sentence-reading task was administered first, followed by the Simon arrow task, TOWREs, semantic judgment tasks, and LEQ. The TOWREs and semantic judgment tasks were counterbalanced for language across participants. The study was part of a larger test battery in a research collaboration between the University of Western Ontario and McGill University.

\section{Results}

\section{Individual differences measures}

Table 3 presents the means, standard deviations, and ranges for background measures (LEQ, TOWREs, Semantic Judgement, Simon Arrows). Table 4 presents correlations between the: (1) English proficiency measures, (2) French proficiency measures, and (3) RT and Error Simon Effects. To simplify our individual differences analyses, we calculated composite scores for French Proficiency, English Proficiency, and Executive Control using separate Principle Component Analyses (PCAs). We first confirmed that English, French, and Executive Control measures loaded on different factors using a varimax rotation. We then entered the variables for each factor into separate analyses to confirm that they each loaded onto a single factor. Regression coefficients were calculated from the second set of analyses for each participant on each factor; these served as the individual difference scores in subsequent analyses. The variable loadings for each factor are also found in Table 4.

\section{Sentence comprehension}

Accuracy was $93 \%$ for questions on filler sentences, indicating that participants read for meaning. Accuracy for sentences containing French homophones (85\%) was significantly higher $(t$ $(95)=4.92, p<.001)$ than sentences containing spelling control words $(80 \%)$.

\section{Eye movement data}

We examined three early-stage and two late-stage eye movement reading measures. Early-stage measures, taken to reflect initial activation of word representations, included FIRST FIXATION DURATION (FFD; duration of initial fixation), GAZE DURATION (GD, sum of all fixation durations during first pass on a word), and REGRESSIONS OUT $^{1}$ (probability of regressing out of a word to an earlier word). Late-stage measures, taken to reflect post-lexical 
Table 4. Pearson Correlations between Background Measures

\begin{tabular}{|c|c|c|c|c|}
\hline & E1 & E2 & E3 & $\begin{array}{c}\text { English } \\
\text { Composite } \\
\text { Loadings }\end{array}$ \\
\hline \multicolumn{5}{|l|}{ English } \\
\hline E1. AoA & - & & & -.702 \\
\hline E2. TOWRE (words) & $-.47^{\star \star}$ & - & & .832 \\
\hline E3. TOWRE (non-words) & -.07 & $.41^{\star \star}$ & - & .580 \\
\hline \multirow[t]{2}{*}{ E4. Semantic d' } & $-.26^{\star}$ & $.21^{\star}$ & .16 & .540 \\
\hline & $\mathrm{F} 1$ & $\mathrm{~F} 2$ & F3 & $\begin{array}{c}\text { French } \\
\text { Composite } \\
\text { Loadings }\end{array}$ \\
\hline \multicolumn{5}{|l|}{ French } \\
\hline F1. AoA & - & & & -.735 \\
\hline F2. TOWRE (words) & $-.48^{\star \star}$ & - & & .882 \\
\hline F3. TOWRE (non-words) & $-.49^{\star \star}$ & $.84^{\star \star}$ & - & .878 \\
\hline \multirow[t]{2}{*}{ F4. Semantic d' } & $-.48^{\star \star}$ & $.53^{\star \star}$ & $.52^{\star \star}$ & .770 \\
\hline & $\mathrm{EC} 1$ & & & $\begin{array}{c}\text { Executive } \\
\text { Control } \\
\text { Loadings }\end{array}$ \\
\hline \multicolumn{5}{|l|}{ Executive Control } \\
\hline EC1. Simon Effect RT & - & & & .813 \\
\hline EC2. Simon Effect Error & $.32^{\star}$ & & & .813 \\
\hline
\end{tabular}

Note: $\mathrm{AoA}=$ age of acquisition

integration, included REGRESSIONS IN (probability of regressing back into a word from a later word) and TOTAL READING TIME (TRT, sum of all fixation and re-fixation durations on a word). Although skipping rates were also examined, there were no significant differences between the critical French conditions (all $z s<1$ ); thus, analyses are not reported. Means for word type by word frequency for each measure are presented in Table 5.

Across the experiment, $0.4 \%$ of the trials were removed because of track loss and/or skimming (i.e., failure to fixate on large portions of the sentences). Data from trials with fixation durations less than $80 \mathrm{~ms}$ were discarded $(\mathrm{FFD}=23, \mathrm{GD}=23$, TRT $=20$ ). No upper cutoff was applied to fixations; rather, analyses were performed on log-transformed data.

The data were analyzed using linear mixed-effects models (LMMs) within the lme4 package (Bates \& Sarkar, 2006) of $\mathrm{R}$ (version 3.3.0) (Baayen, 2008; Baayen, Davidson \& Bates, 2008; R Development Core Team, 2017). Logistic generalized linear mixed models (GLMMs) were used for the regression data. The specifications of each model (e.g., fixed and random effects structure) are reported for each analysis to follow. Only effects of theoretical interest are reported in the text. Complete model outputs can be found in Appendices B through $\mathrm{H}$.

For ease of data interpretation, we first present the analyses of homophone effects. In these analyses, fixed effects included word type (French homophones vs. French control words) and word frequency (high vs. low); both variables were deviation-coded $(0.5,-0.5)^{2}$. Control predictors included word length (continuous), orthographic similarity to the unseen English homophone (continuous), and phonological similarity of the French homophone to the unseen English homophone (continuous); continuous variables were scaled (i.e., $\mathrm{z}$-scored) ${ }^{3}$. Random effects included random intercepts for participants and items, and random slope adjustments for word type across participants ${ }^{4}$. Initially, maximal random effect structures were employed, where both word type and word frequency were included in the participant random slope. However, several models failed to converge; thus, word frequency was dropped from the random slope for all analyses. Subsequently, we conducted separate analyses where each composite score was included as a fixed effect, along with word type and word frequency. The $p$-values were derived using Satterthwaite approximations of degrees of freedom in the lmerTest function, an approach found to produce acceptable Type 1 error rates (Luke, 2017).

\section{Homophone facilitation effects}

\section{Early-stage measures}

A marginal effect of word type was found for FFD $(\beta=-0.02, S E$ $=0.01, t=-1.77, p=.08)$ and GD $(\beta=-0.03, S E=0.002, t=$ $-1.63, p=.10$ ); fixations were marginally shorter for homophones than for control words. Although the interactions of word type and word frequency were non-significant for both $\operatorname{FFD}(\beta=$ $-0.03, S E=0.02, t=-1.25, n s)$ and GD $(\beta=-0.03, S E=0.003$, $t=-0.83, n s)$, our prediction that the homophone effect would be significant for high-frequency words was confirmed (FFD: $\beta$ $=-0.02, S E=0.01, t=-2.07, p<.05$; GD: $\beta=-0.02, S E=0.01, t$ $=-1.92, p=.06)$. The effect was not significant for low-frequency words (FFD: $\beta=-0.01, S E=0.01, t=-0.74, n s$; GD: $\beta=-0.01$, $S E=0.01, t=-0.68, n s)$.

A significant two-way interaction between word type and word frequency $(\beta=0.43, S E=0.14, z=2.96, p<.01)$ was found for Regressions Out. Sub-models of word frequency revealed that the homophone effect occurred for low-frequency words $(\beta=$ $-0.30, \quad S E=0.10, \quad z=-2.92, \quad p<.01)$; fewer regressions out occurred for low-frequency French homophones than for control words. The homophone effect was non-significant for highfrequency words $(\beta=0.13, S E=0.10, z=1.31, n s)$.

\section{Late-stage measures}

A significant effect of word type was found for both Regressions In $(\beta=-0.30, S E=0.08, z=-3.61, p<.001)$ and TRT $(\beta=-0.12$, $S E=0.03, t=-3.74, p<.001)$; fewer regressions in and shorter reading times occurred for French homophones than for French control words. No other effects were observed.

\section{Summary}

Interlingual homophone errors were less disruptive than spelling control errors. In the immediate eye-tracking measures, this effect was seen in fixation durations for high-frequency words, whereas for low-frequency words this effect was seen in regressions made from the target word. Both late-stage measures showed a robust interlingual homophone facilitation effect, indicating that French homophones were easier to integrate into the English sentences than French spelling control words.

\section{Individual differences effects}

\section{French proficiency}

The three-way interaction between word type, word frequency, and French proficiency approached significance in the early measures (FFD: $\beta=-0.04, S E=0.02, t=1.84, p=.06$; GD: $\beta=0.04$, $S E=0.02, t=1.86, p=.06)$, and was firmly established in the 
Table 5. Means and Standard Deviations for Eye Movement Measures as a function of Word Type and Word Frequency

\begin{tabular}{|c|c|c|c|c|c|c|}
\hline \multirow[b]{2}{*}{ Measure } & \multicolumn{3}{|c|}{ High Frequency } & \multicolumn{3}{|c|}{ Low Frequency } \\
\hline & $\begin{array}{l}\text { English } \\
\text { Homophone }\end{array}$ & $\begin{array}{c}\text { French } \\
\text { Homophone }\end{array}$ & $\begin{array}{l}\text { French } \\
\text { Control }\end{array}$ & $\begin{array}{c}\text { English } \\
\text { Homophone }\end{array}$ & $\begin{array}{c}\text { French } \\
\text { Homophone }\end{array}$ & $\begin{array}{l}\text { French } \\
\text { Control }\end{array}$ \\
\hline First Fixation (in ms) & $266(10.8)$ & $286(13.6)$ & $300(15.8)$ & $268(12.1)$ & $289(14.7)$ & $294(12.5)$ \\
\hline Gaze Duration (in ms) & $291(13.9)$ & $326(18.9)$ & $342(20.8)$ & $292(14.9)$ & $340(18.1)$ & $353(21.9)$ \\
\hline Total Time (in ms) & $377(29.1)$ & $583(53.1)$ & $680(68.6)$ & $370(25.8)$ & $560(49.6)$ & $697(66.5)$ \\
\hline Regression Out (in \%) & $16.3(3.8)$ & $22.3(4.3)$ & $20.7(4.1)$ & $14.9(3.6)$ & $19.1(4.0)$ & $23.0(4.3)$ \\
\hline Regression In (in \%) & $22.2(4.2)$ & $40.0(5.0)$ & $44.6(5.1)$ & $19.2(4.0)$ & $37.6(4.9)$ & $42.1(5.1)$ \\
\hline Skipping (in \%) & $31.1(4.7)$ & $27.1(4.5)$ & $26.0(4.5)$ & $29.2(4.6)$ & $21.7(4.2)$ & $20.3(4.1)$ \\
\hline
\end{tabular}

late measures (TRT: $\beta=0.08, \quad S E=0.03, \quad t=2.65, \quad p<.01$; Regressions In: $\beta=0.23, S E=0.11, z=2.65, p<.01)$. Models were then run separately for low- and high-frequency French words. For low-frequency words, fixations were influenced by French proficiency. In FFD, shorter fixations related to greater French proficiency $(\beta=-0.03, S E=0.02, t=-2.12, p<.05)$. The interaction between word type and French proficiency was not significant in FFD $(\beta=-0.01, S E=0.01, t=-0.72, n s)$, but approached significance in GD $(\beta=-0.02, S E=0.01, t=-1.83$, $p=.07)$. This interaction was significant in TRT $(\beta=-0.07, S E$ $=0.03, t=-2.69, p<.01)$ and Regressions In $(\beta=-0.11, S E=$ $0.04, z=-2.83, p<.01)$. Here, higher French proficiency scores related to larger homophone facilitation effects (See Figure 2).

For high-frequency words, there was no interaction between word type and French proficiency (FFD: $\beta=0.01, S E=0.01, t=$ $0.90, n s$; GD: $\beta=0.01, S E=0.01, t=0.66, n s$; TRT: $\beta=0.01, S E$ $=0.02, t=0.35$, ns; Regressions In: $\beta=0.01, S E=0.04, t=0.19$, $n s$; Regressions Out: $\beta=0.01, S E=0.10, t=0.15, n s)$. However, the main effect of word type as reported above was still present for high-frequency words, particularly in the early measures (FFD: $\beta=-0.02, S E=0.01, t=-2.07, p<.05$; GD: $\beta=-0.02, S E$ $=0.01, t=-1.92, p=.06$; TRT: $\beta=-0.08, S E=0.05, t=-1.78, p$ $=.08$ ); fixations were shorter for homophones than for control words.

\section{English proficiency}

There was no influence of English proficiency (see Appendix D). However, the English word knowledge variable had a low factor loading, and, thus, was not well captured by the English composite score. English word knowledge is key to readers' ability to activate the English meaning from the shared phonology. A subsequent analysis was conducted with English word knowledge ( $d$ ' scores) as a fixed factor. For the early-stage measures, there was a significant two-way interaction between word type and English word knowledge for Regressions Out $(\beta=-0.15$, SE = $0.06, z=-2.27, p<.05$ ); better English word knowledge related to more regressions out of control words than interlingual homophones. A marginal three-way interaction between word type, word frequency, and English word knowledge for GD $(\beta=$ $-0.04, S E=0.02, t=-1.80, p=.07)$ indicated that better English word knowledge related to larger homophone effects in highfrequency words.

For the late-stage measures, there was a significant two-way interaction between word type and English word knowledge for TRT $(\beta=-0.03, S E=0.01, t=-2.25, p<.05)$; better English word knowledge related to longer reading times for control words than for interlingual homophones. There was also a threeway interaction between word type, word frequency, and English word knowledge for Regressions In $(\beta=0.24, S E=0.11, z=2.26$, $p<.05)$. For low-frequency words, better English word knowledge related to more regressions into control words than into interlingual homophones (see Figure 3).

\section{Executive control ability}

For early-stage measures, although better executive control related to longer initial fixations on French words (FFD: $\beta=-0.02, S E=$ $0.01, t=-1.80, p<.08$; GD: $\beta=-0.04, S E=0.02, t=-2.28, p$ $<.05)$, this variable did not modulate the homophone effect. In contrast, for TRT, there was a significant three-way interaction between word type, word frequency, and executive control ability $(\beta=-0.07, S E=0.03, t=-2.26, p<.05)$. Sub-models of word frequency revealed a significant interaction between word type and executive control ability $(\beta=0.07, S E=0.03, t=2.68, p<.01)$ for low-frequency words only (see Figure 4 ). Smaller executive control composite scores (i.e., better executive control) related to longer reading times for control words than for interlingual homophones.

\section{Summary}

The interlingual homophone effect was modulated by individual differences in participant skills, primarily for low-frequency words during late-stage reading. In particular, participants who were more proficient in French showed a larger homophone facilitation effect for low-frequency words. Likewise, participants with greater executive control ability showed a larger homophone facilitation effect. Larger homophone effects were also found for those with better English word knowledge, regardless of word frequency.

\section{Discussion}

This study is novel in two key ways: (1) It is the first to examine the dynamics of cross-language phonologically-mediated meaning activation through the use of eye-tracking, which can disentangle early- and late-stage processing and (2) It is the first to examine how individual differences in language proficiency and executive control impact the nature of this activation. A homophone error paradigm using English sentences with French interlingual homophones and their French control words was employed. Shorter/fewer fixations on homophones relative to their spelling control words indicated that shared phonology activated the meaning of the corresponding English homophone, and 


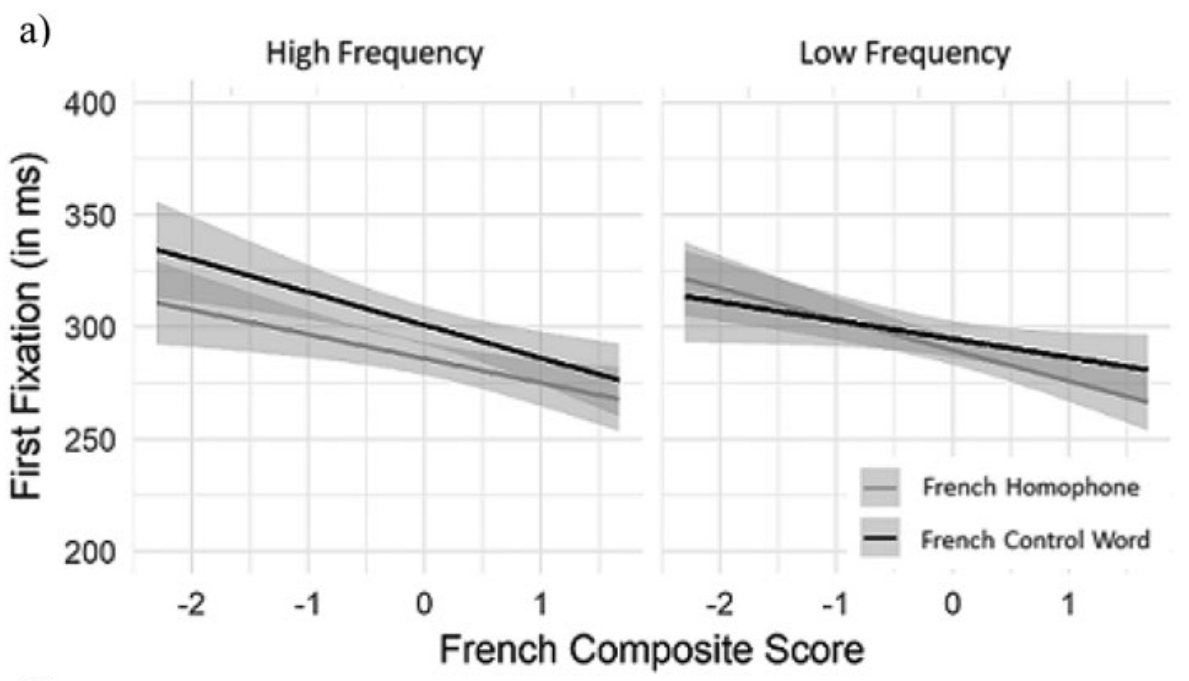

b) High Frequency

Low Frequency

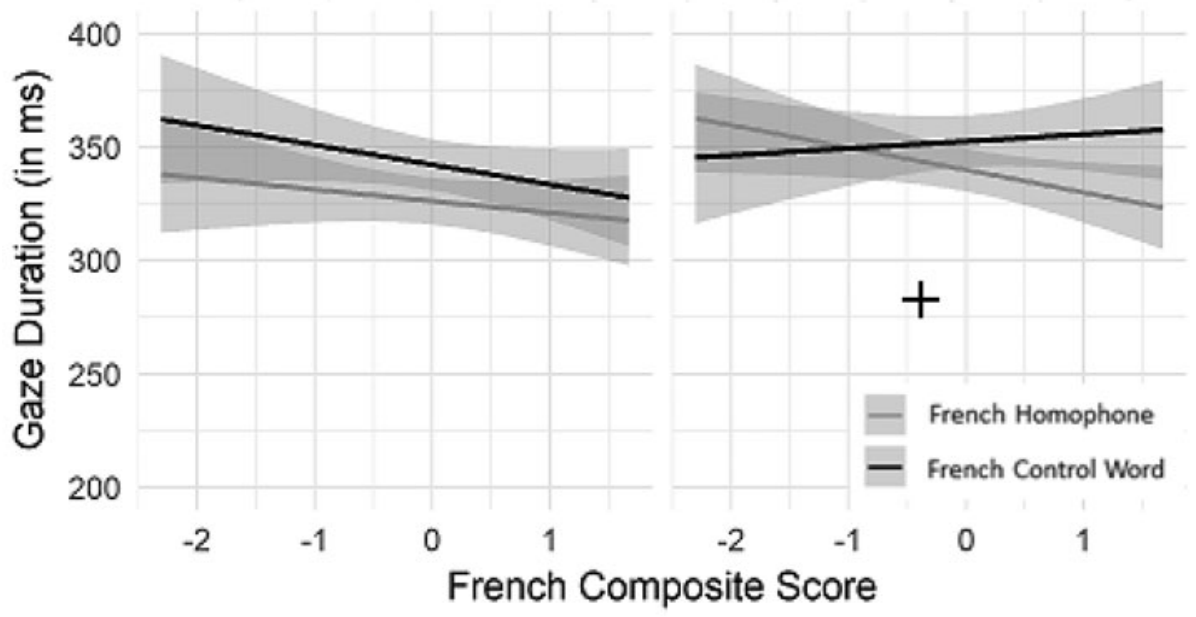

c) High Frequency Low Frequency

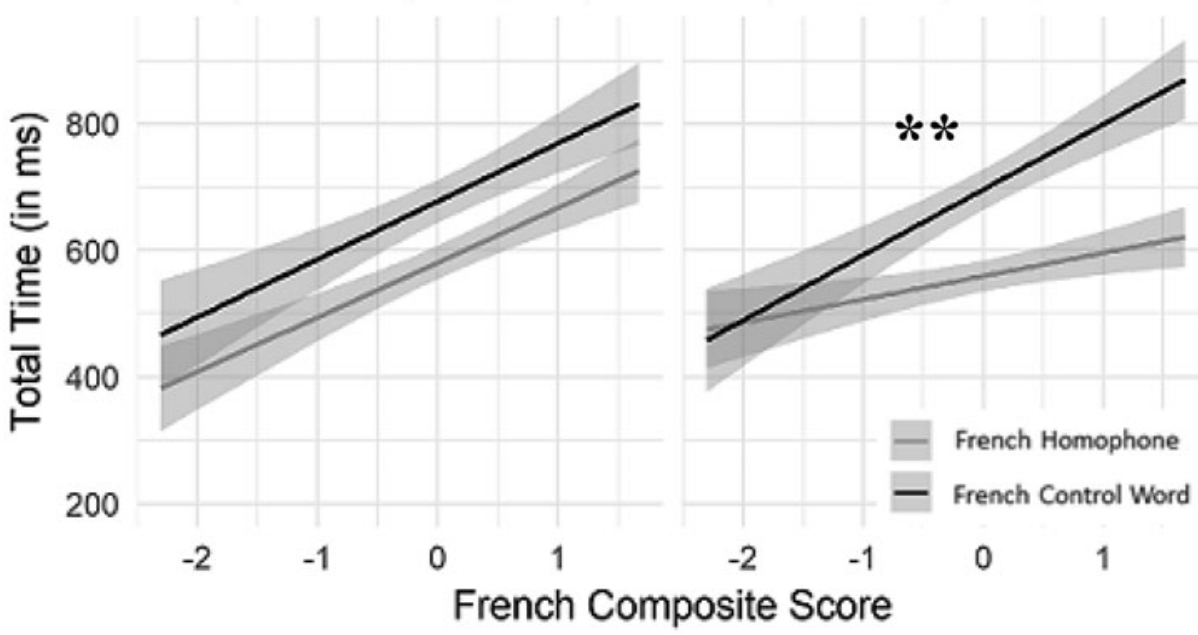

Figure 2. First Fixation (a), Gaze Duration (b), and Total Reading Time (c) as a function word type, word frequency, and French proficiency. Actual values are plotted. Shaded areas represent confidence intervals. Interactions are marked: $+p<.1$, ${ }^{\star \star} p<.01$

that readers incorporated this meaning into their understanding of the sentences.

Below we discuss our findings, starting with the core effects, and then how they were influenced by our individual differences measures. Recall that the early-stage reading measures (FFD, GD, and Regressions Out) are most relevant to understanding initial activation of word representations and that data from the late-stage measures (Regressions In, TRT) reflect the ease 


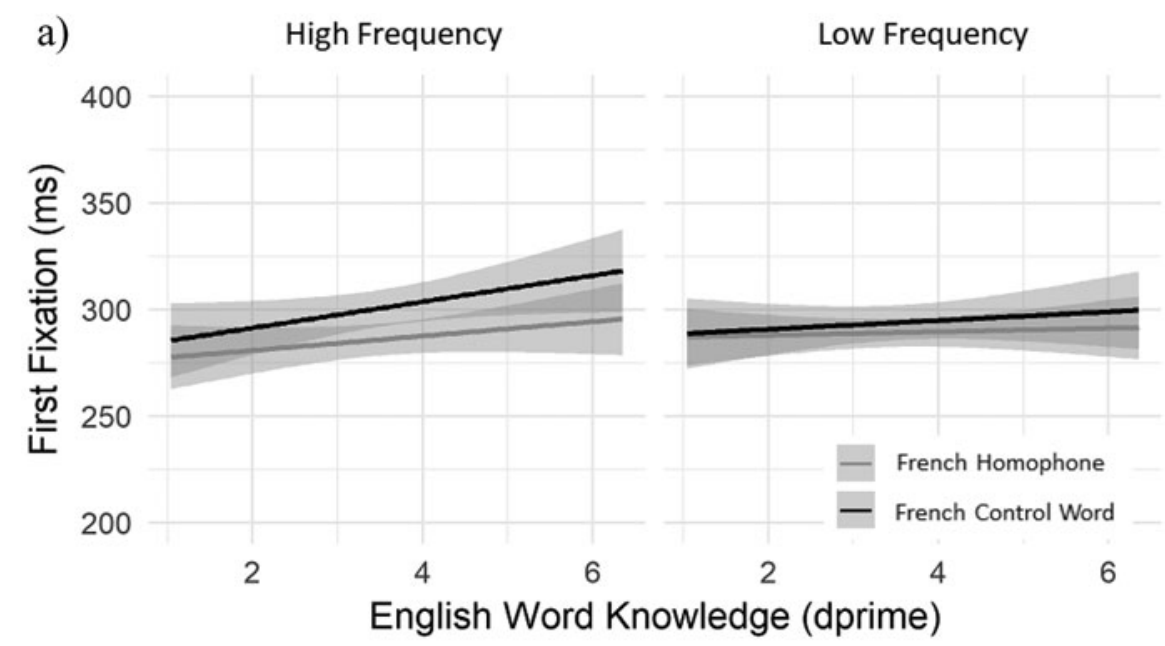

b)

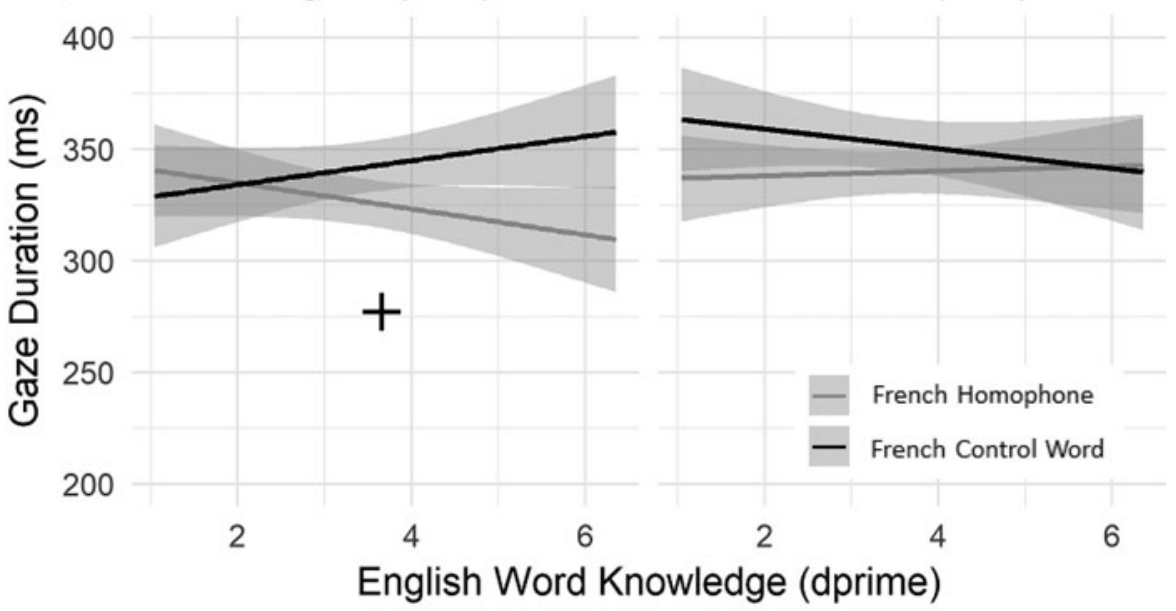

High Frequency

Low Frequency

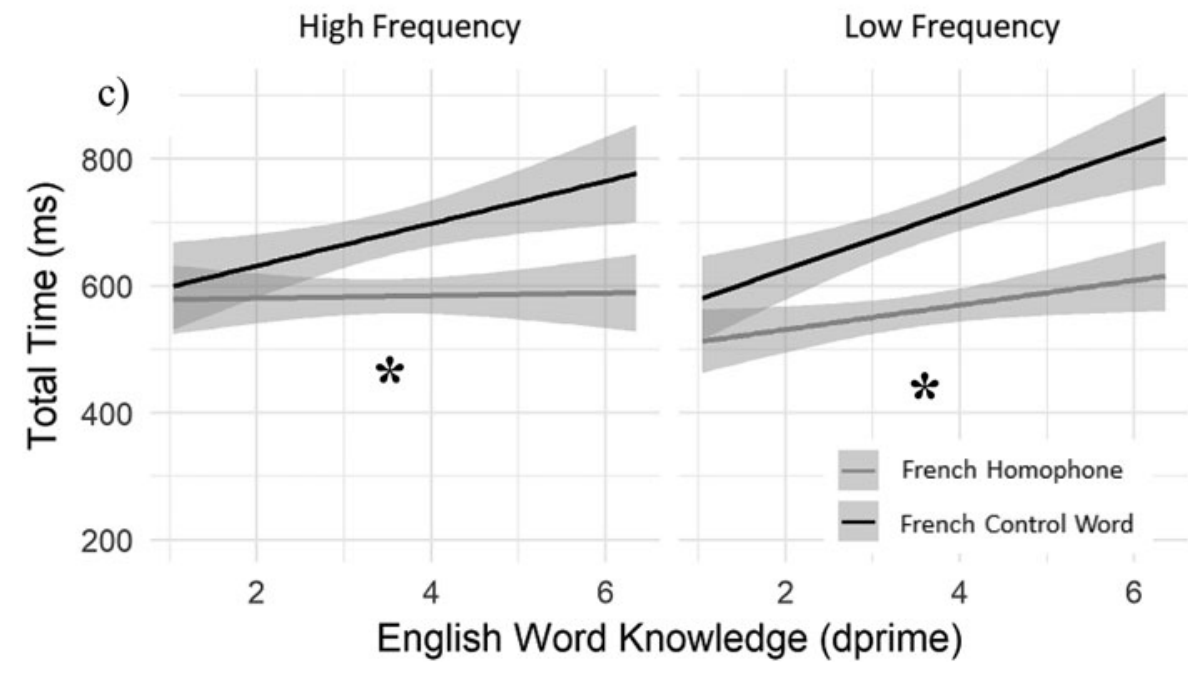

Figure 3. First Fixation (a), Gaze Duration (b), and Total Reading Time (c) as a function of word type, word frequency, and English word knowledge. Actual values are plotted. Shaded areas represent confidence intervals. Interactions are marked: ${ }^{+} p<.1,{ }^{\star} p<.05$

with which participants integrated the meanings activated by the French error words into their understanding of the sentences.

\section{Homophone facilitation effects}

Analyses of core effects revealed that French interlingual homophone errors were less disruptive to reading than French spelling control errors when initially encountered. Readers exhibited marginally shorter fixations on homophone errors than on spelling control errors for early-stage fixation measures; an effect that reached significance for the high-frequency words. These results are consistent with previous findings of facilitatory interlingual homophone effects in single word reading tasks (e.g., CarrascoOrtiz et al., 2012; Friesen et al., 2014; Haigh \& Jared, 2007; 


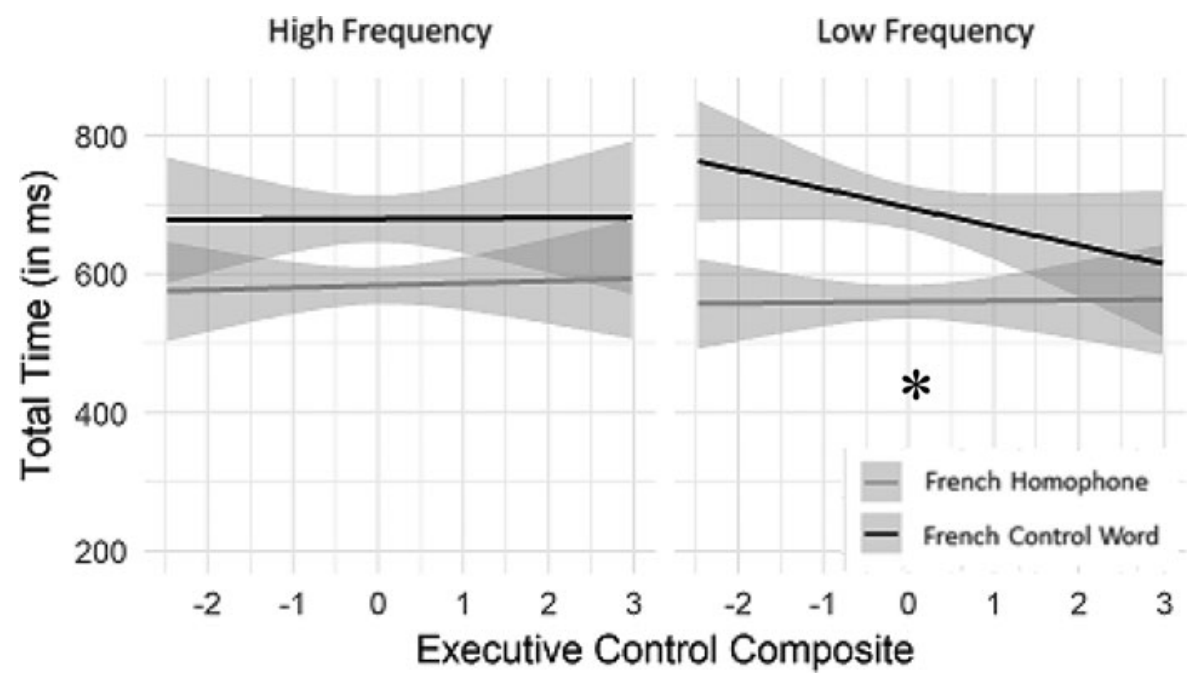

Figure 4. Total Reading Time as a function of word type, word frequency, and executive control composite score. Actual values are plotted. Shaded areas represent confidence intervals. Interactions are marked: ${ }^{*} p<.05$
Lemhöfer \& Dijkstra, 2004), and provide additional support that readers activate phonological representations that are shared across languages. However, here we demonstrate these effects on initial word processing, in the absence of a response-based task (e.g., lexical decision), suggesting that some phonological activation occurs during initial lexical processing rather than once a word has been identified ${ }^{5}$.

This facilitatory homophone effect could further reflect activation to semantic representations associated with the unseen English homophone. As our sentence ratings showed, the meanings associated with the English homophones were more plausible continuations of the initial sentence contexts than either French meaning. Activating the meanings associated with the English members of the homophone pairs would, therefore, facilitate reading even in the early measures. Corroborating evidence that these English meanings were indeed quickly activated comes from our finding that fewer regressions were made from lowfrequency homophone errors than from spelling controls, because regressions are indicative of anomaly detection. Notably, we found evidence of early phonological activation, even in the absence of a strong biasing context. Most studies provide a biasing context that allows for a "head start" to maximize the likelihood of observing homophone effects (e.g., FitzPatrick \& Indefrey, 2014; Newman \& Connolly, 2004; Niznikiewicz \& Squires, 1996; Savill et al., 2011).

The TRT and Regressions In measures capture participants' ability to integrate the French error words into the English sentence. For the French homophone to be successfully integrated, its phonological representation must be activated from print, and that phonological representation must, in turn, activate the semantics associated with the English homophone. If TRTs for interlingual homophones and spelling control errors do not differ, it suggests that participants were not activating shared phonology and/or were unable to retrieve the English meaning associated with the shared phonology. Results were more robust for latestage reading measures than for early-stage ones. Readers found it easier to integrate the French homophones into their understanding of the sentence, as evidenced by shorter TRTs and fewer regressions into the critical region for homophones relative to control words, suggesting that meanings associated with the English members of French interlingual homophones were all eventually activated.
Our late-stage reading results are consistent with responsebased tasks like category verification, which report robust phonological effects when top-down information is provided (e.g., Friesen et al., 2016; Jared \& Seidenberg, 1991; van Orden, 1987). In our task, the region after the target word provided some disambiguating information, allowing the reader to understand the sentence only if they activated the English meaning. Similarly, Friesen and Jared (2012) reported that bilinguals were slower and less accurate in correctly rejecting homophones (e.g., shoe) as category members (e.g., vegetable) when the unseen homophone mate (e.g., /chou/ cabbage) was a category member. Although numerous studies have found that words in one language activate phonological representations for words in the other language, only a few have demonstrated that these phonological representations were activated strongly enough to activate their corresponding semantic representations from the other language.

\section{Individual differences}

Although the core effects analyses revealed that readers were accessing cross-language meaning through shared phonology, individual differences variables provided a more nuanced story of the dynamics of lexical activation. Both language experience and executive control ability influenced lexical activation. Specifically, participant characteristics (e.g., French proficiency, executive control) had a greater influence on the processing of low-frequency words than of high-frequency words, and the influence of these individual difference measures was more robust during late-stage reading than in early-stage reading.

\section{French language proficiency}

As noted, the homophone effect for high-frequency words was not influenced by French proficiency; in general, readers spent less time processing homophones than their control words. Presumably for all French users, the phonological representations of these words were quickly and strongly activated. As these words were more familiar, their shared phonological code was readily accessible, leading to activation of the associated English meaning.

Individual differences in French proficiency did influence the processing of low-frequency words; more proficient French users were more likely to exhibit facilitatory homophone effects. The influence of French proficiency began as early as FFD and 
was fully realized in TRT. Given that less proficient French users had ample time to activate phonological representations, it is likely that the phonological representations that they generated from the low-frequency French interlingual homophones were not accurate enough to activate the meaning associated with the English homophone. Note that low proficiency French users had low scores on the French TOWRE, indicating weaker word reading fluency and decoding skills. In contrast, more proficient French readers would have activated phonological representations from the low-frequency French homophones quickly and strongly, making it more likely that subsequent activation of English semantic representations would be detectable.

The finding that language ability modulated the homophone facilitation effect for low-frequency words is consistent with research in both the monolingual and bilingual literatures. In a monolingual version of our task, Jared and colleagues (1999) reported that reader skill influenced the size of homophone effects. Likewise, Gollan and colleagues (2008) reported that language experience influenced naming latencies for low-frequency items more than high-frequency items in a picture naming task, such that the difference between monolingual and bilingual naming latencies was much more pronounced for the low-frequency items.

Leading models of bilingual language processing, such as BIA+ (Dijkstra \& van Heuven, 2002) and the weaker links hypothesis (Gollan et al., 2008), provide frequency-based explanations of lexical processing that can account for our results. These models assume that lexical representations have different baseline activation levels as a function of exposure; high-frequency words have higher baseline activation levels than low-frequency words because they are, by definition, encountered more often. However, there are diminishing returns; once a representation reaches a certain activation level, additional exposures have little impact on its representation or its processing, as is the case with high-frequency words. In contrast, additional encounters with low-frequency words may increase their activation levels and, ultimately, strengthen the connections between orthographic and phonological representations. Accordingly, low-frequency words should be more sensitive to individual differences in French exposure. As expected, our individual difference effects were strongest for low-frequency words.

\section{English language proficiency}

Our English composite score was not associated with homophone effects; however, a specific component - English word knowledge was the most relevant variable. It was only weakly associated with other proficiency measures and did not load well on the English composite. Yet, results revealed as accuracy on the English semantic judgment task increased, processing differences between spelling controls and French homophones also increased. Better English knowledge was associated with more regressions out of spelling controls than out of French homophones, suggesting better English word knowledge enables readers to integrate the homophones into their initial understanding, whereas repair processes were necessary for spelling controls. Strong connections between shared phonological representations and English meanings allow the English meaning to be sufficiently activated from the French homophone.

English word knowledge and word frequency exerted different influences on early versus late fixation measures. In TRT, the relationship between English word knowledge and homophone effects was not influenced by French word frequency. This is likely because the English homophones were all of low frequency (e.g., leer, mare) and, consequently, both French frequency conditions required strong English vocabulary knowledge. However, notably, in Figure 3 there is a hint that the interaction between English word knowledge and word type emerges earlier (i.e., on GD) in the high-frequency condition, but not in the low-frequency condition. If, as we saw from our core effects analysis, high-frequency French homophones initially activate the shared phonology strongly in all readers, then individual differences in the strength of phonology-semantic connections (e.g., mov (mow) to "cut grass") may be detected more readily for these words relative to low-frequency words.

\section{Executive control}

Our measure of executive control ability (as assessed by a Simon Arrows task) was sufficiently sensitive to capture individual differences in readers' attention to critical words. Overall, better executive control was associated with longer initial fixations on French words. That is, individuals who ignored irrelevant information better in the executive control task maintained more initial attention on the anomalous words, perhaps recognizing these words' importance for their ultimate understanding of the sentence. The ability to monitor comprehension and maintain attention to relevant information is critical while reading for meaning. However, during early-stage reading, executive control ability was not associated with homophone facilitation effects. This finding suggests that domain-general executive control is not being engaged to either inhibit the activation of French spelling-sound correspondences in an English context or inhibit the English meaning when encountering a French homophone. Instead, activation appears to spread across the word recognition system in a language non-selective manner.

It is only when readers are integrating the word meaning into their understanding of the sentence that an effect of executive control ability on homophone processing is observed. Better executive control ability was associated with larger homophone effects in TRT for low-frequency words. This effect can be attributed to participants' increased efforts to incorporate the French control word into their understanding of the sentences, rather than quicker processing of homophones. Indeed, participants had already retrieved the homophones' relevant meaning and did not require re-analysis of the sentence. Although this effect may be counterintuitive, recall that participants were instructed to read the sentences for meaning and better executive control ability enables readers to strategically modulate their reading behaviors to meet the demands of the task.

To date, the findings are mixed about whether executive control ability operates within the word recognition system to impact identification. Recall that Pivneva and colleagues (2014) reported less homograph interference in GD for individuals with greater executive control. Friesen and Haigh (2018) reported smaller interlingual priming effects for individuals with better ability to suppress the non-target language. However, Prior, Degani, Awawdy, Yassin, and Korem (2017) found no relationship between the degree of L1 interference in an L2 semantic similarity judgment task and performance on executive control measures of inhibition and task switching. Here, we did not observe an influence of executive control on homophone effects during earlystage reading. However, in our task, there was no value in engaging executive control processes to initially suppress or ignore the English meaning of the French homophone since this meaning facilitated understanding of the sentence. Our results suggest that engaging executive control processes to 
immediately suppress the non-target meaning does not happen automatically upon encountering the interlingual word. Future studies should design sentences that clearly bias readers against activating the non-target language meaning of a homophone pair. If inhibitory effects of executive control ability are present during early-stage reading, they should be more readily detectable.

\section{Theoretical implications}

There are several important theoretical implications that arise from our findings. First, consistent with the architecture and principles of BIA+, the indirect pathway to meaning (orthographyphonology-semantics) can be used to activate cross-language meaning in a language non-selective manner during the initial stages of word recognition. While there have been numerous studies showing that printed words in one language can activate phonological representations corresponding to words in the other language (e.g, Carrasco-Ortiz et al., 2012; Dijkstra et al., 1999; Haigh \& Jared, 2007; Lemhöfer \& Dijkstra, 2004), there was little available evidence demonstrating that activation from phonological representations could, in turn, activate associated semantic representation from the other language. Clear support for the use of this pathway comes from evidence that strong French phonological representations (indexed by higher French proficiency) and strong English semantic knowledge (indexed by greater accuracy on the English semantic judgment task) result in larger homophone effects. Second, the differential impact of word frequency and language skill are consistent with the importance of experience highlighted in both BIA+ (Dijkstra \& van Heuven, 2002) and the weaker links hypothesis (Gollan et al., 2008). Individuals with higher levels of language proficiency were more strongly impacted by homophony.

As seen in Table 5, participants had much shorter fixation durations on the English members of the homophone pairs than on the French words. The original BIA model (Dijkstra \& van Heuven, 1998) had top-down inhibitory connections from the language nodes, and could explain this finding by assuming that when reading English sentences, participants inhibited French lexical representations. The current instantiation of BIA + does not have these top-down inhibitory connections from the language nodes, and assumes that lexical representations from each language are available for selection based on their current resting activation levels. The model could explain our findings by assuming that English words generally had higher resting activation levels than French words. The specific English homophones were not predictable from the context, as our sentence completion results demonstrate, and, thus, the higher resting activation levels would have to be more general. However, the model also assumes that activated words inhibit one another, and it is unclear what the accumulated impact of this inhibition would be as participants read English sentences.

Pivneva and colleagues (2014) raised another important concern, which is that BIA+ does not specify a role for domaingeneral executive control ability. In their study, they found that greater executive control ability related to less interlingual homograph intereference, indexed by shorter fixation durations during early-stage reading. We too observed that individuals with better executive control modulated their reading behaviors by allocating more time to processing French words during early-stage reading. However, this effect was not specific to interlingual homophones, but rather reflected attention to anomalous words. This finding suggests that executive control impacted general reading behaviors rather than language non-selectivity. The distinction between domain-general executive control processes operating on the language system and inhibition within the codes of the language system is an important one for models of language processing. In their Adaptive Control Hypothesis, Green and Abutalebi (2013) propose that the degree to which control is engaged depends on the bilingual nature of the context, and that systematically varying task demands may shed light on how control is utilized during language processing. Future research should further explore the relative contributions of domain-general control processes and control processes specific to the language system on crosslanguage activation during natural reading in bilinguals.

\section{Limitations and future directions}

Our study used an interlingual homophone error paradigm, in which sentences were in English and on critical trials the French member of the interlingual homophone pair replaced the English mate (Lemhöfer et al., 2018, also replaced target language words with words from the bilinguals' other language in a sentence reading study). The presence of French words may have encouraged our participants to keep both languages active (e.g., Kreiner \& Degani, 2015; Mercier, Pivneva \& Titone, 2016), even though only $2.6 \%$ of the encountered words were in French. This co-activation may have exaggerated the homophone effects. However, we confirmed that the homophone effects did not increase as the experiment progressed (across both reading stages), suggesting that participants were not becoming more strategic. Now that we have found clear evidence for cross-language semantic activation from phonology using this paradigm, the next step would be to make the manipulation subtler and only use words from a single language. An English sentence could contain an interlingual homophone, but have the French meaning fit the sentence (e.g., Kristin made a coleslaw using chopped shoe and carrots). Similarly, a French sentence could contain an interlingual homophone, but have the English meaning fit the sentence (e.g., Michelle a marché dans une flaque d'eau et son chou est complètement mouillé - Michelle walked into a puddle and her cabbage (shoe) is completely wet). Reading times on interlingual homophones would need to be compared to spelling control words. We would hypothesize that homophone effects are most likely to occur when participants are highly fluent in the non-target language.

\section{Conclusion}

Our study demonstrates that phonologically-mediated crosslanguage meaning activation occurs during both early- and latestage reading. Our focus on individual differences in language proficiency and executive control ability allowed us to gain a better understanding of the dynamics operating during reading for meaning. Greater French proficiency, English semantic knowledge, and executive control ability were all associated with differences in how meaning was accessed. Future models of bilingual language processing would greatly benefit from research treating bilingualism and its constituent components along a continuum rather than dichotomously.

\section{Author ORCIDs. (iD) Deanna C. Friesen, 0000-0002-1510-6102}

We thank Lorin Alarachi, Naomi Vingron, Paige Palenski, and Vincent Rouillard for their assistance with data collection. Veronica Whitford is now at the Department of Psychology, University of Texas at El Paso. This work 
was supported by Natural Sciences and Engineering Research Council of Canada Discovery Grants awarded to DJ and to DT.

\section{References}

Ando E, Jared D, Nakayama M, \& Hino Y (2014) Cross-script phonological priming with Kanji primes and English targets. Journal of Cognitive Psychology 26, 858-870. doi: 10.1080/20445911.2014.971026

Ando E, Matsuki K, Sheridan H, \& Jared D (2015) The locus of Katakana-English masked phonological priming effects. Bilingualism: Language and Cognition 18, 101-117. doi:10.1017/S1366728914000121

Baayen HR (2008) Analyzing linguistic data: A practical introduction to statistics using R. New York, NY: Cambridge University Press. http://dx.doi.org/ 10.1017/CBO9780511801686

Baayen HR, Davidson DJ, \& Bates DM (2008) Mixed-effects modeling with crossed random effects for subjects and items. Journal of Memory and Language 59, 390-412. http://dx.doi.org/10.1016/j.jml.2007.12.005

Baayen RH, Piepenbrock R, \& van Rijn H (1993) The CELEX lexical database (CD-ROM). Philadelphia, PA: University of Pennsylvania. Linguistic Data Consortium.

Bates D, \& Sarkar D (2006) lme4: Linear mixed-effects modeling using S4 classes $R$ package (Version 0.9975-10). Vienna, Austria: R Foundation for Statistical Computing.

Brysbaert M, Van Dyck G, \& Van de Poel M (1999) Visual word recognition in bilinguals: Evidence from masked phonological priming. Journal of Experimental Psychology: Human Perception and Performance 25, 137148. doi:10.1037/0096-1523.25.1.137

Carrasco-Ortiz H, Midgley KJ, \& Frenck-Mestre C (2012), Are phonological representations in bilinguals language specific? An ERP study on interlingual homophones. Psychophysiology 49, 531-543. doi:10.1111/ j.1469-8986.2011.01333.x

Clifton Jr. C, Staub A, \& Rayner K (2007) Eye movements in reading words and sentences. In RPG van Gompel, MH Fischer, WS Murray \& RL Hill (Eds.), Eye movements: $A$ window on mind and brain; eye movements: $A$ window on mind and brain (pp. 341-371) Elsevier, Amsterdam. doi:10.1016/B978-008044980-7/50017-3

Daneman M, \& Reingold E (1993) What eye fixations tell us about phonological receding during reading. Canadian Journal of Experimental Psychology 47, 153-178. doi: 10.1037/h0078818

Daneman M, Reingold EM, \& Davidson M (1995) Time course of phonological activation during reading: Evidence from eye fixations. Journal of Experimental Psychology: Learning, Memory, and Cognition 21, 884-898. doi: 10.1037/0278-7393.21.4.884

Davis CJ (2005) N-Watch: A program for deriving neighborhood size and other psycholinguistic statistics. Behavior Research Methods 37, 65-70.

Degani T, Prior A, \& Hajajra W (2017) Cross-language semantic influences in different script bilinguals. Bilingualism: Language and Cognition. Advance online publication. doi:10.1017/S1366728917000311

Dijkstra T, Grainger J, \& van Heuven WJB (1999) Recognition of cognates and interlingual homographs: The neglected role of phonology. Journal of Memory and Language 41, 496-518. doi: 10.1006/jmla.1999.2654

Dijkstra T, \& van Heuven WJB (1998) The BIA model and bilingual word recognition. In J Grainger \& AM Jacobs (Eds.), Localist connectionist approaches to human cognition (pp. 189-225). Mahwah, NJ: Erlbaum.

Dijkstra T, \& van Heuven WJB (2002) The architecture of the bilingual word recognition system: From identification to decision. Bilingualism: Language and Cognition 5, 175-197. doi: 10.1017/S1366728902003012

Duyck W (2005) Translation and associative priming with cross-lingual pseudohomophones: Evidence for nonselective phonological activation in bilinguals. Journal of Experimental Psychology: Learning, Memory, and Cognition 31, 1340-1359. doi:10.1037/0278-7393.31.6.1340

Duyck W, Diependaele K, Drieghe D, \& Brysbaert M (2004) The size of the cross-lingual masked phonological priming effect does not depend on second language proficiency. Experimental Psychology 51, 116-124. doi: 10.1027/1618-3169.51.2.116

Feng G, Miller K, Shu H, \& Zhang H (2001) Rowed to recovery: The use of phonological and orthographic information in reading Chinese and
English. Journal of Experimental Psychology: Learning, Memory, and Cognition 27, 1079-1100. doi: 10.1037/0278-7393.27.4.1079

Friesen D.C., \& Haigh CA (2018) Cross-language associative priming in influenced by language proficiency and executive control. The Canadian Journal of Experimental Psychology 72(4), 264-276. doi:10.1037/cep0000155.

Friesen DC, \& Jared D (2012) Cross-language phonological activation of meaning: Evidence from category verification. Bilingualism: Language and Cognition 15, 145-156. doi:10.1017/S1366728910000489

Friesen DC, Jared D, \& Haigh C.A. (2014) Phonological processing dynamics in bilingual word naming. Canadian Journal of Experimental Psychology 68, 179-193. doi: 10.1037/cep0000026

Friesen DC, Oh J, \& Bialystok E (2016) Phonologically-mediated meaning activation in monolinguals and bilinguals: Evidence from homophone effects in ERP. Linguistic Approaches to Bilingualism 6, 262-289. doi:10.1037/0278-7393.33.4.623

FitzPatrick I, \& Indefrey P (2014) Head start for target language in bilingual listening. Brain Research 1542, 111-130. doi: 10.1016/ j.brainres.2013.10.014

Gollan TH, Montoya RI, Cera C, \& Sandoval TC (2008) More use almost always means a smaller frequency effect: Aging, bilingualism, and the weaker links hypothesis. Journal of Memory and Language 58 787-814. doi: 10.1016/j.jml.2007.07.001

Green D.W., \& Abutalebi J (2013) Language control in bilinguals: The adaptive control hypothesis. Journal of Cognitive Psychology 25, 515-530. doi: 10.1080/20445911.2013.796377

Haigh CA, \& Jared D (2007) The activation of phonological representations by bilinguals while reading silently: Evidence from interlingual homophones. Journal of Experimental Psychology: Learning, Memory, \& Cognition 33, 623-644. doi: 10.1037/0278-7393.33.4.623

Harm MW, \& Seidenberg MS (2004) Computing the meanings of words in reading: Cooperative division of labor between visual and phonological processes. Psychological Review 111, 662-720. doi:10.1037/0033295X.111.3.662

Hoversten L J., \& Traxler M.J. (2016) Time course analysis of interlingual homograph processing: Evidence from eye movements. Bilingualism: Language and Cognition 19, 347-360. doi:10.1017/S1366728915000115

Jared D (2015) Literacy and literacy development in bilinguals. In A Pollatsek \& R Treiman (Eds.), The Oxford handbook of reading (pp. 165-182). New York: Oxford University Press.

Jared D, Cormier P, Levy BA, \& Wade-Woolley L (2011) Early predictors of biliteracy development in children in French Immersion: A 4-Year longitudinal study. Journal of Educational Psychology 103, 119-139. doi: 10.1037/ a0021284

Jared D, \& Kroll J (2001) Do bilinguals activate phonological representations in one or both of their languages when naming words? Journal of Memory and Language 44, 2-31. doi: 10.1006/jmla.2000.2747

Jared D, Levy BA, \& Rayner K (1999) The role of phonology in the activation of word meanings during reading: Evidence from proof-reading and eye movements. Journal of Experimental Psychology: General 128, 219-264. doi: 10.1037/0096-3445.128.3.219

Jared D, \& O'Donnell K (2017) Skilled, adult readers activate the meanings of high-frequency words using phonology: Evidence from eye-tracking. Memory \& Cognition 45, 334-346. doi: 10.3758/s13421-016-0661-4.

Jared D, \& Seidenberg MS (1991) Does word identification proceed from spelling to sound to meaning? Journal of Experimental Psychology: General 120, 358-394. doi:10.1037/0096-3445.120.4.358

Kreiner H, \& Degani T (2015) Tip-of-the-tongue in a second language: the effects of brief first language exposure and long-term use. Cognition 137, 106-114. doi: .1016/j.cognition.2014.12.011

Kuperman V, Drieghe D, Keuleers E, \& Brysbaert M (2013) How strongly do word reading times and lexical decision times correlate? Combining data from eye movement corpora and megastudies. Quarterly Journal of Experimental Psychology 66, 563-580. doi: 10.1080/17470218.2012.658820

Landauer T.K., Foltz P.W., \& Laham D (1998) An introduction to latent semantic analysis. Discourse Processes 25, 259-284.

Lauro J, \& Schwartz AI (2017) Bilingual non-selective lexical access in sentence contexts: A meta-analytic review. Journal of Memory and Language 92, 217-233. doi: 10.1016/j.jml.2016.06.010 
Lemhöfer K, \& Dijkstra T (2004) Recognizing cognates and interlingual homographs: Effects of code similarity in language-specific and language generalized lexical decision tasks. Memory \& Cognition 32, 533-550. doi:10.3758/BF03195845

Lemhöfer K, Huestegge L, \& Mulder K (2018) Another cup of TEE? The processing of second language near-cognates in first language reading. Language, Cognition \& Neuroscience 33, 968-991. doi:10.1080/23273798.2018.1433863

Libben MR, \& Titone DA (2009) Bilingual lexical access in context: Evidence from eye movements during reading. Journal of Experimental Psychology: Learning, Memory, and Cognition 35, 381-390. doi: 10.1037/a00114875

Luke S.G. (2017) Evaluating significance in linear mixed-effects models in R. Behavior Research Methods 49, 1494-1502. doi: 10.3758/s13428-016-0809-y

Martin-Rhee MM, \& Bialystok E (2008) The development of two types of inhibitory control in monolingual and bilingual children. Bilingualism: Language and Cognition 11, 81-93. doi:10.1037/t67362-000

Mercier J, Pivneva I, \& Titone D (2016) The role of prior language context on bilingual spoken word processing: Evidence from the visual world task. Bilingualism: Language \& Cognition 19, 376-399.

New B, Pallier C, Brysbaert M, \& Ferrand L (2004) Lexique 2: A New French Lexical Database. Behavior Research Methods, Instruments, \& Computers 36 (3), 516-524. http://www.lexique.org

Newman RL, \& Connolly JF (2004) Determining the role of phonology in silent reading using event-related brain potentials. Cognitive Brain Research 21, 94-105. doi:10.1016/j.cogbrainres.2004.05.006

Newman RL, Jared D, \& Haigh CA (2012) Does phonology play a role when skilled readers read high-frequency words? Evidence from ERPs. Language and Cognitive Processes 27, 1361-1384. doi:10.1080/01690965.2011.603932

Niznikiewicz M, \& Squires NK (1996) Phonological processing and the role of strategy in silent reading: Behavioral and electrophysiological evidence. Brain and Language 52, 342-364. doi:10.1006/brln.1996.0016

Pivneva I, Mercier J, \& Titone D (2014) Executive control modulates crosslanguage lexical activation during L2 reading: Evidence from eye movements. Journal of Experimental Psychology: Learning, Memory \& Cognition 40, 787-796. doi:10.1037/a0035583

Prior A, Degani T, Awawdy S, Yassin R, \& Korem N (2017) Is susceptibility to cross-language interference domain specific? Cognition 165, 10-25. doi: 10.1016/j.cognition.2017.04.006

Rayner K, Pollatsek A, \& Binder KS (1998) Phonological codes and eye movements in reading. Journal of Experimental Psychology: Learning, Memory, and Cognition 24, 476-497. doi: 10.1037/0278-7393.24.2.476

Savill N, Lindell A, Booth A, West G, \& Thierry G (2011) Literate humans sound out words during silent reading. NeuroReport: For Rapid Communication of Neuroscience Research 22, 116-120. doi:10.1097/ WNR.0b013e328342ed27

Schwartz AI, \& Kroll JF (2006) Bilingual lexical activation in sentence context. Journal of Memory and Language 55, 197-212. doi:10.1016/ j.jml.2006.03.004
Schotter ER (2013) Synonyms provide semantic preview benefit in English. Journal of Memory and Language 69, 619-633. doi: 10.1016/ j.jml.2013.09.002

Sunderman G, \& Fancher E (2013) Lexical access in bilinguals and second language learners. In J.W. Schwieter (Ed.), Innovative research and practices in second language acquisition and bilingualism (pp. 267-286). Amsterdam, Netherlands: John Benjamins Publishing Company.

Titone D, Libben M, Mercier J, Whitford V, \& Pivneva I (2011) Bilingual lexical access during L1 sentence reading: The effects of L2 knowledge, semantic constraint, and L1-L2 intermixing. Journal of Experimental Psychology: Learning, Memory and Cognition 37, 1412-1431. doi: 10.1037/a0024492

Titone D, Pivneva I, Sheikh N, Webb N, \& Whitford V (2015) Doubling down on multifactorial approaches to the study of bilingualism and executive control. Bilingualism: Language and Cognition 18, 43-44.

Titone D, Whitford V, Lijewska A, \& Itzhak I (2016) Bilingualism, executive control, and eye movement measures of reading: A selective review and re-analysis of bilingual vs. multilingual reading data (pp. 11-46). In J Schwieter (Ed.), Cognitive control and consequences in the multilingual mind. Amsterdam, Netherlands: John Benjamins Publishing Company.

Torgesen JK, Wagner RK, \& Rashotte CA (1999) Test of Word Reading Efficiency. Austin, TX: Pro-Ed.

van Assche E, Drieghe D, Duyck W, Welvaert M, \& Hartsuiker RJ (2011) The influence of semantic constraints on bilingual word recognition during sentence reading. Journal of Memory and Language 64, 88-107. doi:10.1016/j.jml.2010.08.006

van Orden GC (1987) A ROWS is a ROSE: Spelling, sound, and reading. Memory \& Cognition 15, 181-198. doi:10.3758/BF03197716

van Orden GC, Johnston JC, \& Hale BL (1988) Word identification in reading proceeds from spelling to sound to meaning. Journal of Experimental Psychology: Learning, Memory, and Cognition 14,371-386. doi:10.1037/0278-7393.14.3.371

van Wijnendaele I, \& Brysbaert M (2002) Visual word recognition in bilinguals: Phonological priming from the second to the first language. Journal of Experimental Psychology: Human Perception \& Performance 28, 616-627. doi: 10.1037/0096-1523.28.3.616

Whitford V, \& Luk G (in press) Comparing executive functions in monolinguals and bilinguals: Considerations on participant characteristics and statistical assumptions in current research. In I Sekerina, V Valian, \& L Spradlin (Eds.), Bilingualism and executive function: An interdisciplinary approach (pp. 1-30). Amsterdam: John Benjamins.

Whitford V, Pivneva I, \& Titone D (2016) Eye movement methods to investigate bilingual reading. In RR Heredia, J Altarriba, \& AB Cieślicka (Eds.), Methods in bilingual reading comprehension research (pp. 183-212). New York, NY: Springer-Verlag.

Ziegler JC, Benraïss A, \& Besson M (1999) From print to meaning: An electrophysiological investigation of the role of phonology in accessing meaning. Psychophysiology 36, 775-785. doi:10.1017/S0048577299980952 


\section{Appendix A: Critical Stimuli}

\begin{tabular}{|c|c|c|c|c|c|}
\hline \multicolumn{3}{|l|}{ High Frequency } & \multicolumn{3}{|c|}{ Low Frequency } \\
\hline English Homophone & French Homophone & French Control & English Homophone & French Homophone & French Control \\
\hline Bun & Bonne (good) & Bois (wood) & Bee & Bille (marble) & Beurre (butter) \\
\hline Crew & Cru (believed) & Cri (shouted) & Boo & Boue (mud) & Bol (bowl) \\
\hline Fee & Fille (girl) & Feu (fire) & Cask & Casque (helmet) & Casse (break) \\
\hline Foe & Faux (should) & Faim (hungry) & Clue & Clou (nail) & Colle (glue) \\
\hline Fool & Foule (mob) & Foi (faith) & Knee & Nid (nest) & Noix (nut) \\
\hline Leer & Lire (read) & Livre (book) & Lease & Lisse (smooth) & Laine (wool) \\
\hline Pen & Peine (pain) & Peur (fear) & Pool & Poule (hen) & Pouce (thumb) \\
\hline Rear & Rire (laugh) & Rouge (red) & Queer & Cuire (cook) & Couvre (cover) \\
\hline Sank & Cinq (five) & Soeur (sister) & Rush & Roche (stone) & Ronge (snore) \\
\hline Shack & Chaque (each) & Soir (evening) & Sear & Cire (wax) & Cils (eyelash) \\
\hline Sue & Sous (under) & Suis (follow) & Sew & Seau (bucket) & Saut (jump) \\
\hline Tie & Taille (height) & Triste (sad) & Shoe & Chou (cabbage) & Cloche (clock) \\
\hline Wheat & Huit (eight) & Hier (yesterday) & Toe & Taux (toll) & Tige (stem) \\
\hline
\end{tabular}


Appendix B: Core Effects

\begin{tabular}{|c|c|c|c|c|c|c|c|c|c|c|c|c|c|c|c|}
\hline \multirow[b]{2}{*}{ Fixed Effects } & \multicolumn{3}{|c|}{ First Fixation Duration ${ }^{\dagger}$} & \multicolumn{3}{|c|}{ Gaze Duration $^{\dagger}$} & \multicolumn{3}{|c|}{ Total Reading Time } & \multicolumn{3}{|c|}{ Regressions Out $^{\dagger}$} & \multicolumn{3}{|c|}{ Regressions In } \\
\hline & $\beta$ & $S E$ & $t$ & $\beta$ & $S E$ & $t$ & $\beta$ & $S E$ & $t$ & $\beta$ & $S E$ & $z$ & $\beta$ & $S E$ & $z$ \\
\hline Word Type & -0.023 & 0.013 & $-1.77^{+}$ & -0.027 & 0.002 & -1.63 & -0.122 & 0.033 & $-3.74^{\star \star \star}$ & -0.085 & 0.072 & -1.18 & -0.299 & 0.083 & $-3.61^{\star \star \star}$ \\
\hline Word Frequency & -0.009 & 0.012 & -0.74 & -0.024 & 0.002 & $-1.50+$ & 0.033 & 0.032 & 1.04 & 0.040 & 0.075 & 0.54 & 0.113 & 0.086 & 1.31 \\
\hline Word Type X Frequency & -0.030 & 0.024 & -1.25 & -0.026 & 0.003 & $-0.83+$ & 0.073 & 0.060 & 1.22 & 0.428 & 0.144 & $2.96^{\star \star}$ & 0.226 & 0.167 & 1.36 \\
\hline Control Predictors & $\beta$ & $S E$ & $t$ & $\beta$ & $S E$ & $t$ & $\beta$ & $S E$ & $t$ & $\beta$ & $S E$ & $z$ & $\beta$ & $S E$ & $z$ \\
\hline Word Length & -0.011 & 0.006 & $-1.74^{+}$ & 0.027 & 0.008 & $3.36^{\star \star}$ & 0.063 & 0.016 & $4.03^{\star \star \star}$ & -0.104 & 0.037 & $-2.81^{\star \star}$ & 0.158 & 0.043 & $3.68^{\star \star \star}$ \\
\hline Orthographic Similarity & 0.013 & 0.006 & $2.23^{\star}$ & 0.008 & 0.008 & $1.00^{\star \star \star}$ & -0.036 & 0.016 & $-2.33^{\star}$ & -0.130 & 0.036 & $-3.62^{\star \star \star}$ & -0.132 & 0.042 & $-3.13^{\star \star}$ \\
\hline Phonological Similarity & -0.001 & 0.006 & -0.11 & 0.001 & 0.008 & 0.09 & -0.001 & 0.015 & -0.65 & -0.018 & 0.036 & -0.50 & -0.024 & 0.042 & -0.56 \\
\hline Intercept & 5.59 & 0.016 & $357.6^{\star \star \star}$ & 5.70 & 0.020 & $290.2^{\star \star \star}$ & 6.15 & 0.038 & $163.08^{\star \star \star}$ & -1.56 & 0.110 & $-14.2^{\star \star \star}$ & -0.362 & 0.091 & $-3.98^{\star \star \star}$ \\
\hline \multirow{2}{*}{ Random Effects } & \multicolumn{3}{|c|}{ Variance } & \multicolumn{3}{|c|}{ Variance } & \multicolumn{3}{|c|}{ Variance } & \multicolumn{3}{|c|}{ Variance } & \multicolumn{3}{|c|}{ Variance } \\
\hline & Intercept & & Slope $^{1}$ & Intercept & & Slope $^{1}$ & Intercept & & Slope $^{1}$ & Intercept & & Slope & Intercept & & Slope \\
\hline Participants & 0.020 & & 0.001 & 0.031 & & 0.003 & 0.114 & & 0.015 & 0.985 & & - & 0.624 & & - \\
\hline Items & 0.001 & & & 0.002 & & & 0.013 & & & 0.011 & & - & 0.075 & & - \\
\hline Residual & \multicolumn{3}{|c|}{0.132} & \multicolumn{3}{|c|}{0.180} & \multicolumn{3}{|c|}{0.343} & \multicolumn{3}{|c|}{-} & \multicolumn{3}{|c|}{-} \\
\hline
\end{tabular}

${ }^{+} p<.1,{ }^{\star} p<.05,{ }^{\star \star} p<.01,{ }^{\star \star \star} p<.001$

${ }^{1}$. Random slope adjustments for word type across participants.

stage measures. 


\section{Appendix C: French Proficiency}

\begin{tabular}{|c|c|c|c|c|c|c|c|c|c|c|c|c|c|c|c|}
\hline \multirow[b]{2}{*}{ Fixed Effects } & \multicolumn{3}{|c|}{ First Fixation Duration $^{\dagger}$} & \multicolumn{3}{|c|}{ Gaze Duration $^{\dagger}$} & \multicolumn{3}{|c|}{ Total Reading Time } & \multicolumn{3}{|c|}{ Regressions Out $^{\dagger}$} & \multicolumn{3}{|c|}{ Regressions In } \\
\hline & $\beta$ & $S E$ & $t$ & $\beta$ & $S E$ & $t$ & $\beta$ & $S E$ & $t$ & $\beta$ & $S E$ & $z$ & $\beta$ & $S E$ & $z$ \\
\hline Word Type & -0.023 & 0.013 & $-1.76^{=}$ & -0.027 & 0.016 & -1.63 & -0.123 & 0.032 & $-3.79^{\star \star \star}$ & -0.080 & 0.072 & -1.11 & -0.297 & 0.083 & $-3.57^{\star \star \star}$ \\
\hline Word Frequency & -0.009 & 0.012 & -0.74 & -0.024 & 0.016 & -1.49 & 0.033 & 0.032 & 1.04 & 0.051 & 0.075 & 0.68 & 0.109 & 0.087 & 1.26 \\
\hline French Proficiency & -0.038 & 0.015 & $-2.50^{\star}$ & -0.020 & 0.020 & -1.03 & 0.073 & 0.035 & $2.10^{*}$ & -0.211 & 0.107 & -1.97 & 0.347 & 0.078 & $4.46^{\star \star \star}$ \\
\hline Word Type X Frequency & -0.030 & 0.024 & -1.25 & -0.026 & 0031 & -0.84 & 0.073 & 0.060 & 1.21 & 0.420 & 0.145 & $2.89^{\star *}$ & 0.217 & 0.167 & 1.30 \\
\hline Word Type X French Proficiency & -0.002 & 0.012 & -0.21 & -0.001 & 0.013 & -0.75 & -0.031 & 0.019 & -1.57 & 0.046 & 0.069 & 0.66 & -0.102 & 0.054 & $-1.90^{+}$ \\
\hline Frequency $\mathrm{X}$ French Proficiency & -0.012 & 0.010 & -1.20 & -0.018 & 0.019 & -1.54 & 0.022 & 0.015 & 1.43 & 0.101 & 0.069 & 1.46 & 0.086 & 0.054 & 1.59 \\
\hline $\begin{array}{l}\text { Word Type X Frequency X French } \\
\text { Proficiency }\end{array}$ & 0.037 & 0.020 & $1.84^{=}$ & 0.044 & 0.024 & $1.86^{+}$ & 0.080 & 0.030 & $2.65^{\star \star}$ & -0.065 & 0.139 & -0.47 & 0.231 & 0.108 & $2.15^{\star}$ \\
\hline Control Predictors & $\beta$ & SE & $t$ & $\beta$ & SE & $t$ & $\beta$ & $S E$ & $t$ & $\beta$ & $S E$ & $z$ & $\beta$ & SE & $z$ \\
\hline Word Length & -0.011 & 0.006 & $-1.74^{+}$ & 0.027 & 0.008 & $3.37^{\star \star}$ & 0.063 & 0.016 & $4.04^{* \star \star}$ & -0.105 & 0.037 & $-2.83^{\star \star}$ & 0.159 & 0.043 & $3.69^{\star \star \star}$ \\
\hline Orthographic Similarity & 0.013 & 0.006 & $2.25^{\star}$ & 0.008 & 0.008 & 1.01 & -0.036 & 0.016 & $-2.33^{*}$ & -0.131 & 0.036 & $-3.63^{\star \star \star}$ & -0.132 & 0.042 & $-3.13^{\star \star}$ \\
\hline Phonological Similarity & -0.001 & 0.006 & -0.10 & 0.001 & 0.008 & 0.10 & -0.010 & 0.015 & -0.63 & -0.018 & 0.036 & -0.49 & -0.023 & 0.042 & -0.55 \\
\hline Intercept & 5.59 & 0.015 & $366.5^{\star \star \star}$ & 5.70 & 0.020 & $290.0^{\star \star \star}$ & 6.16 & 0.037 & $165.5^{\star \star \star}$ & -1.56 & 0.107 & $-14.6^{\star \star \star}$ & -0.365 & 0.084 & $-4.34^{\star \star \star}$ \\
\hline \multirow{2}{*}{ Random Effects } & \multicolumn{3}{|c|}{ Variance } & \multicolumn{3}{|c|}{ Variance } & \multicolumn{3}{|c|}{ Variance } & \multicolumn{3}{|c|}{ Variance } & \multicolumn{3}{|c|}{ Variance } \\
\hline & Intercept & & Slope $^{1}$ & Intercept & & Slope $^{1}$ & Intercept & & Slope $^{1}$ & Intercept & & Slope & Intercept & & Slope \\
\hline Participants & 0.019 & & 0.003 & 0.031 & & 0.003 & 0.110 & & 0.014 & 0.937 & & - & 0.506 & & - \\
\hline Items & 0.001 & & & 0.002 & & & 0.013 & & & 0.011 & & - & 0.075 & & - \\
\hline Residual & \multicolumn{3}{|c|}{0.132} & \multicolumn{3}{|c|}{0.180} & \multicolumn{3}{|c|}{0.342} & \multicolumn{3}{|c|}{ - } & \multicolumn{3}{|c|}{ - } \\
\hline
\end{tabular}

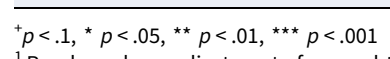

Random slope adjustments for word type across participants.

${ }^{\dagger}$ Indicates early-stage measures. 


\begin{tabular}{|c|c|c|c|c|c|c|c|c|c|c|c|c|c|c|c|}
\hline \multirow[b]{2}{*}{ Fixed Effects } & \multicolumn{3}{|c|}{ First Fixation Duration ${ }^{\dagger}$} & \multicolumn{3}{|c|}{ Gaze Duration $^{\dagger}$} & \multicolumn{3}{|c|}{ Total Reading Time } & \multicolumn{3}{|c|}{ Regressions Out ${ }^{\dagger}$} & \multicolumn{3}{|c|}{ Regressions In } \\
\hline & $\beta$ & $S E$ & $t$ & $\beta$ & $S E$ & $t$ & $\beta$ & $S E$ & $t$ & $\beta$ & $S E$ & $z$ & $\beta$ & $S E$ & $z$ \\
\hline Word Type & -0.023 & 0.013 & $-1.78^{+}$ & -0.027 & 0.016 & -1.63 & -0.122 & 0.033 & $-3.74^{\star \star \star}$ & -0.082 & 0.072 & -1.14 & -0.300 & 0.083 & $-3.60^{\star \star \star}$ \\
\hline Word Frequency & -0.009 & 0.012 & -0.74 & -0.024 & -0.016 & -1.50 & 0.033 & 0.032 & 1.04 & 0.036 & 0.075 & 0.49 & 0.113 & 0.086 & 1.30 \\
\hline English Proficiency & 0.013 & 0.015 & 0.84 & -0.006 & 0.019 & -0.36 & -0.013 & 0.035 & -0.36 & 0.165 & 0.106 & 1.55 & -0.060 & 0.084 & -0.72 \\
\hline $\begin{array}{l}\text { Word Type X } \\
\text { Frequency }\end{array}$ & -0.030 & 0.024 & -1.24 & -0.025 & 0.031 & -0.83 & 0.073 & 0.060 & 1.21 & 0.424 & 0.145 & $2.93^{\star \star}$ & 0.227 & 0.167 & 1.36 \\
\hline $\begin{array}{l}\text { Word Type X } \\
\text { English Proficiency }\end{array}$ & 0.005 & 0.012 & 0.44 & -0.037 & 0.013 & -0.28 & -0.013 & 0.020 & -0.65 & -0.039 & 0.071 & -0.55 & 0.024 & 0.052 & 0.47 \\
\hline $\begin{array}{l}\text { Frequency } \mathrm{X} \\
\text { English Proficiency }\end{array}$ & 0.018 & 0.010 & $1.73^{+}$ & 0.020 & 0.12 & $1.66^{+}$ & -0.004 & 0.015 & -0.25 & 0.064 & 0.071 & 0.90 & -0.046 & 0.052 & -0.89 \\
\hline $\begin{array}{l}\text { Word Type X } \\
\text { Frequency X } \\
\text { English Proficiency }\end{array}$ & -0.013 & 0.020 & -0.63 & 0.00 & 0.024 & -0.01 & -0.019 & 0.030 & -0.61 & 0.062 & 0.142 & 0.44 & 0.072 & 0.104 & 0.69 \\
\hline Control Predictors & $\beta$ & $S E$ & $t$ & $\beta$ & $S E$ & $t$ & $\beta$ & $S E$ & $t$ & $\beta$ & $S E$ & $z$ & $\beta$ & $S E$ & $z$ \\
\hline Word Length & -0.011 & 0.006 & $-1.74^{+}$ & 0.027 & 0.008 & $3.36^{\star *}$ & 0.063 & 0.016 & $4.03^{\star \star \star}$ & -0.104 & 0.037 & $-2.81^{\star \star}$ & 0.158 & 0.043 & $3.68^{\star \star \star}$ \\
\hline $\begin{array}{l}\text { Orthographic } \\
\text { Similarity }\end{array}$ & 0.013 & 0.006 & $2.22^{\star}$ & 0.008 & 0.008 & 0.98 & -0.036 & 0.016 & $-2.32^{\star}$ & -0.131 & 0.036 & $-3.61^{\star \star \star}$ & -0.132 & 0.042 & $-3.14^{\star \star}$ \\
\hline $\begin{array}{l}\text { Phonological } \\
\text { Similarity }\end{array}$ & -0.001 & 0.006 & -0.12 & 0.001 & 0.008 & 0.08 & -0.010 & 0.015 & -0.64 & -0.018 & 0.036 & -0.51 & -0.024 & 0.042 & -0.57 \\
\hline Intercept & 5.59 & 0.016 & $356.8^{\star \star \star}$ & 5.70 & 0.020 & $288.9^{\star \star \star}$ & 6.16 & 0.038 & $162.4^{\star \star \star}$ & -1.56 & 0.108 & $-14.4^{\star \star \star}$ & -0.364 & 0.091 & $-4.01^{\star \star \star}$ \\
\hline \multirow{2}{*}{ Random Effects } & \multicolumn{3}{|c|}{ Variance } & \multicolumn{3}{|c|}{ Variance } & \multicolumn{3}{|c|}{ Variance } & \multicolumn{3}{|c|}{ Variance } & \multicolumn{3}{|c|}{ Variance } \\
\hline & Intercept & & Slope $^{1}$ & Intercept & & Slope ${ }^{1}$ & Intercept & & Slope ${ }^{1}$ & Intercept & & Slope & Intercept & & Slope \\
\hline Participants & 0.020 & & 0.003 & 0.031 & & 0.003 & 0.115 & & 0.015 & 0.955 & & - & 0.621 & & - \\
\hline Items & 0.001 & - & & 0.002 & & & 0.013 & & & 0.012 & & - & 0.075 & & - \\
\hline Residual & \multicolumn{3}{|c|}{0.132} & \multicolumn{3}{|c|}{0.180} & \multicolumn{3}{|c|}{0.343} & \multicolumn{3}{|c|}{-} & \multicolumn{3}{|c|}{-} \\
\hline
\end{tabular}

${ }^{+} p<.1,{ }^{*} p<.05,{ }^{* \star} p<.01,{ }^{* \star *} p<.001$

${ }_{1}^{1}$ Random slope adjustments for word type across participants.

${ }^{\dagger}$ Indicates early-stage measures. 


\begin{tabular}{|c|c|c|c|c|c|c|c|c|c|c|c|c|c|c|c|}
\hline \multirow[b]{2}{*}{ Fixed Effects } & \multicolumn{3}{|c|}{ First Fixation Duration ${ }^{\dagger}$} & \multicolumn{3}{|c|}{ Gaze Duration $^{\dagger}$} & \multicolumn{3}{|c|}{ Total Reading Time } & \multicolumn{3}{|c|}{ Regressions Out ${ }^{\dagger}$} & \multicolumn{3}{|c|}{ Regressions In } \\
\hline & $\beta$ & $S E$ & $t$ & $\beta$ & $S E$ & $t$ & $\beta$ & $S E$ & $t$ & $\beta$ & $S E$ & $z$ & $\beta$ & $S E$ & $z$ \\
\hline Word Type & -0.023 & 0.013 & $-1.70^{+}$ & -0.026 & 0.017 & -1.59 & -0.123 & 0.032 & $-3.79^{\star \star \star}$ & -0.071 & 0.073 & -0.98 & -0.306 & 0.083 & $-3.67^{\star \star \star}$ \\
\hline Word Frequency & -0.007 & 0.013 & -0.55 & -0.022 & 0.016 & -1.40 & 0.033 & 0.032 & 1.03 & 0.046 & 0.076 & 0.60 & 0.105 & 0.087 & 1.21 \\
\hline $\begin{array}{l}\text { English Word } \\
\text { Knowledge }\end{array}$ & 0.008 & 0.016 & 0.49 & -0.007 & 0.019 & -0.34 & 0.032 & 0.036 & 0.90 & 0.161 & 0.108 & 1.50 & 0.071 & 0.086 & 0.83 \\
\hline $\begin{array}{l}\text { Word Type X } \\
\text { Frequency }\end{array}$ & -0.031 & 0.024 & -1.29 & -0.026 & 0.031 & -0.85 & 0.071 & 0.061 & 1.17 & 0.417 & 0.147 & $2.84^{\star \star}$ & 0.230 & 0.167 & 1.38 \\
\hline $\begin{array}{l}\text { Word Type X English } \\
\text { Word Knowledge }\end{array}$ & -0.006 & 0.012 & -0.52 & -0.013 & 0.013 & -0.96 & -0.044 & 0.019 & $-2.30^{\star}$ & -0.152 & 0.067 & $-2.27^{\star}$ & -0.005 & 0.054 & -0.09 \\
\hline $\begin{array}{l}\text { Frequency } X \text { English } \\
\text { Word Knowledge }\end{array}$ & 0.018 & 0.010 & $1.73^{+}$ & 0.014 & 0.011 & 1.19 & -0.034 & 0.015 & $-2.25^{\star}$ & -0.037 & 0.067 & -0.55 & -0.087 & 0.054 & -1.62 \\
\hline $\begin{array}{l}\text { Word Type } X \\
\text { Frequency X English } \\
\text { Word Knowledge }\end{array}$ & -0.001 & 0.020 & -0.04 & -0.043 & 0.024 & $-1.80^{+}$ & -0.008 & 0.030 & -0.27 & 0.125 & 0.134 & 0.93 & 0.242 & 0.107 & $2.26^{\star}$ \\
\hline Control Predictors & $\beta$ & $S E$ & $t$ & $\beta$ & $S E$ & $t$ & $\beta$ & $S E$ & $t$ & $\beta$ & $S E$ & $z$ & $\beta$ & SE & $z$ \\
\hline Word Length & -0.010 & 0.006 & -1.58 & 0.027 & 0.008 & $3.45^{\star \star \star}$ & 0.064 & 0.016 & $4.06^{\star \star \star}$ & -0.108 & 0.038 & $-2.87^{\star \star}$ & 0.156 & 0.043 & $3.63^{\star \star \star}$ \\
\hline $\begin{array}{l}\text { Orthographic } \\
\text { Similarity }\end{array}$ & 0.014 & 0.006 & $2.23^{*}$ & 0.008 & 0.008 & 1.04 & -0.036 & 0.016 & $-2.29^{\star}$ & -0.125 & 0.037 & $-3.40^{\star \star \star}$ & -0.132 & 0.042 & $-3.12^{\star \star}$ \\
\hline $\begin{array}{l}\text { Phonological } \\
\text { Similarity }\end{array}$ & -0.001 & 0.006 & -0.15 & 0.001 & 0.008 & 0.09 & -0.010 & 0.015 & -0.63 & -0.014 & 0.036 & -0.38 & -0.024 & 0.042 & -0.57 \\
\hline Intercept & 5.59 & 0.016 & $352.4^{\star \star \star}$ & 5.70 & 0.020 & $286.0^{\star \star \star}$ & 6.16 & 0.038 & $161.4^{\star \star \star}$ & -1.56 & 0.110 & $-14.24^{\star \star \star}$ & -0.357 & 0.092 & $-3.90^{\star \star \star}$ \\
\hline \multirow{2}{*}{ Random Effects } & \multicolumn{3}{|c|}{ Variance } & \multicolumn{3}{|c|}{ Variance } & \multicolumn{3}{|c|}{ Variance } & \multicolumn{3}{|c|}{ Variance } & \multicolumn{3}{|c|}{ Variance } \\
\hline & Intercept & & Slope $^{1}$ & Intercept & & Slope ${ }^{1}$ & Intercept & & Slope ${ }^{1}$ & Intercept & & Slope & Intercept & & Slope \\
\hline Participants & 0.020 & & 0.003 & 0.032 & & 0.003 & 0.115 & & 0.013 & 0.968 & & - & 0.626 & & - \\
\hline Items & 0.001 & & & 0.002 & & & 0.013 & & & 0.013 & & - & 0.075 & & - \\
\hline Residual & \multicolumn{3}{|c|}{0.132} & \multicolumn{3}{|c|}{0.181} & \multicolumn{3}{|c|}{0.344} & \multicolumn{3}{|c|}{ - } & \multicolumn{3}{|c|}{ - } \\
\hline
\end{tabular}

${ }^{+} p<.1,{ }^{\star} p<.05,{ }^{* \star} p<.01,{ }^{\star \star *} p<.001$

1. Random slope adjustments for word type across participants.

${ }^{\dagger}$ Indicates early-stage measures. 


\begin{tabular}{|c|c|c|c|c|c|c|c|c|c|c|c|c|c|c|c|}
\hline \multirow[b]{2}{*}{ Fixed Effects } & \multicolumn{3}{|c|}{ First Fixation Duration ${ }^{\dagger}$} & \multicolumn{3}{|c|}{ Gaze Duration $^{\dagger}$} & \multicolumn{3}{|c|}{ Total Reading Time } & \multicolumn{3}{|c|}{ Regressions Out ${ }^{\dagger}$} & \multicolumn{3}{|c|}{ Regressions In } \\
\hline & $\beta$ & $S E$ & $t$ & $\beta$ & $S E$ & $t$ & $\beta$ & $S E$ & $t$ & $\beta$ & $S E$ & $z$ & $\beta$ & $S E$ & $z$ \\
\hline Word Type & -0.024 & 0.013 & $-1.80^{+}$ & -0.027 & 0.016 & -1.65 & -0.123 & 0.032 & $-3.78^{\star \star}$ & -0.082 & 0.072 & -1.15 & -0.300 & 0.087 & $-3.61^{\star \star \star}$ \\
\hline Word Frequency & -0.009 & 0.012 & -0.74 & -0.024 & 0.016 & -1.50 & 0.033 & 0.032 & 1.03 & 0.043 & 0.075 & 0.58 & 0.112 & 0.086 & 1.30 \\
\hline Executive Control & -0.027 & 0.015 & $-1.80^{+}$ & -0.043 & 0.018 & $-2.28^{\star}$ & -0.025 & 0.035 & -0.73 & -0.115 & 0.108 & -1.07 & 0.027 & 0.084 & 0.32 \\
\hline $\begin{array}{l}\text { Word Type X } \\
\text { Frequency }\end{array}$ & -0.029 & 0.024 & -1.24 & -0.025 & 0.031 & -0.83 & 0.073 & 0.060 & 1.21 & 0.421 & 0.145 & $2.91^{\star \star}$ & 0.225 & 0.167 & 1.35 \\
\hline $\begin{array}{l}\text { Word Type X } \\
\text { Executive Control }\end{array}$ & 0.011 & 0.012 & 0.94 & 0.004 & 0.013 & 0.32 & 0.032 & 0.019 & $1.71^{+}$ & 0.030 & 0.072 & 0.42 & 0.119 & 0.053 & $2.24^{\star}$ \\
\hline $\begin{array}{l}\text { Frequency X } \\
\text { Executive Control }\end{array}$ & -0.009 & 0.010 & -0.89 & -0.006 & 0.012 & -0.51 & 0.013 & 0.015 & 0.85 & 0.030 & 0.072 & 0.70 & 0.108 & 0.053 & $2.04^{\star}$ \\
\hline $\begin{array}{l}\text { Word Type X } \\
\text { Frequency X } \\
\text { Executive Control }\end{array}$ & -0.029 & 0.020 & -1.45 & -0.034 & 0.024 & -1.43 & -0.068 & 0.030 & $-2.26^{\star}$ & -0.133 & 0.144 & -0.92 & 0.066 & 0.106 & 0.62 \\
\hline Control Predictors & $\beta$ & $S E$ & $t$ & $\beta$ & $S E$ & $t$ & $\beta$ & $S E$ & $t$ & $\beta$ & $S E$ & $z$ & $B$ & $S E$ & $z$ \\
\hline Word Length & -0.011 & 0.006 & $-{ }^{-} 1.74^{+}$ & 0.026 & 0.008 & $3.34^{\star \star}$ & 0.063 & 0.016 & $4.03^{\star \star \star}$ & -0.104 & 0.037 & $-2.82^{\star \star}$ & 0.158 & 0.043 & $3.67^{\star \star \star}$ \\
\hline $\begin{array}{l}\text { Orthographic } \\
\text { Similarity }\end{array}$ & 0.013 & 0.006 & $2.22^{\star}$ & 0.008 & 0.008 & 0.99 & -0.036 & 0.016 & $-2.33^{\star}$ & -0.131 & 0.036 & $-3.63^{\star \star \star}$ & -0.132 & 0.042 & $-3.13^{\star \star \star}$ \\
\hline $\begin{array}{l}\text { Phonological } \\
\text { Similarity }\end{array}$ & -0.001 & 0.006 & -0.10 & 0.001 & 0.008 & 0.09 & -0.010 & 0.015 & -0.65 & -0.017 & 0.036 & -0.50 & -0.023 & 0.042 & -0.55 \\
\hline Intercept & 5.59 & 0.015 & $360.7^{\star \star \star}$ & 5.70 & 0.019 & $295.4^{\star \star \star}$ & 6.16 & 0.038 & $162.7^{\star \star \star}$ & -1.56 & 0.109 & $-14.3^{\star \star \star}$ & -0.363 & 0.091 & $-3.98^{\star \star \star}$ \\
\hline \multirow{2}{*}{ Random Effects } & \multicolumn{3}{|c|}{ Variance } & \multicolumn{3}{|c|}{ Variance } & \multicolumn{3}{|c|}{ Variance } & \multicolumn{3}{|c|}{ Variance } & \multicolumn{3}{|c|}{ Variance } \\
\hline & Intercept & & Slope $^{1}$ & Intercept & & Slope $^{1}$ & Intercept & & Slope ${ }^{1}$ & Intercept & & Slope & Intercept & & Slope \\
\hline Participants & 0.019 & & 0.003 & 0.030 & & 0.003 & 0.115 & & 0.014 & 0.974 & & - & 0.625 & & - \\
\hline Items & 0.001 & & & 0.002 & & & 0.013 & & & 0.011 & & - & 0.075 & & - \\
\hline Residual & \multicolumn{3}{|c|}{0.132} & \multicolumn{3}{|c|}{0.180} & \multicolumn{3}{|c|}{0.343} & \multicolumn{3}{|c|}{ - } & \multicolumn{3}{|c|}{-} \\
\hline
\end{tabular}

${ }^{+} p<.1,{ }^{\star} p<.05,{ }^{* \star} p<.01,{ }^{\star \star \star *} p<.001$

Random slope adjustments for word type across participants.

Indicates early-stage measures. 